\title{
A review of latitudinal characteristics of sporadic sodium layers, including new results from the Chinese Meridian project
}

Shican Qiu ${ }^{1,2}$, Yihuan Tang ${ }^{1,2}$, Mingjiao Jia ${ }^{1,2}$, Xianghui Xue ${ }^{1,2}$, Xiankang Dou ${ }^{1,2 *}$, Tao $L i^{1,2}$, Yuhong Wang ${ }^{3}$

${ }^{1}$ School CAS Key Laboratory of Geospace Environment, Department of Geophysics and Planetary Science, University of Science and Technology of China, Hefei, Anhui, 230026, China

${ }^{2}$ Mengcheng National Geophysical Observatory, School of Earth and Space Sciences, University of Science and Technology of China, Hefei, Anhui, 230026, China

${ }^{3}$ Department of Chemistry and Laser Chemistry Institute, Fudan University, Shanghai 200433, China

* Corresponding author: X.K.Dou

E-mail address: (dou@ustc.edu.cn) 


\begin{abstract}
Characteristics of the sporadic sodium layers (SSLs or Nas) in different latitudes and altitudes are summarized in this paper and the possible mechanisms are discussed. The SSLs in high latitude have a maximum frequency near midnight with significant seasonal differences of height and intensity being reported in previous studies. The average height of summer SSLs was much lower than that of winter SSLs and the average density enhancement factor for summer SSLs was much larger than that for winter SSLs. The simultaneous observations of the SSLs and sporadic E layers (Es) suggested that the Es probably contribute significantly to the formation of high latitude SSLs. In contrast, the temperature mechanism seemed to contribute little to the high latitude SSLs, especially since plenty or frequent high latitude SSLs were observed under minimum temperature conditions.
\end{abstract}

The SSLs in the subtropical area from $20^{\circ} \mathrm{N}$ to $35^{\circ} \mathrm{N}$ show similar characteristics between different stations. The onset of SSLs in Hefei $\left(31.8^{\circ} \mathrm{N}, 117.3^{\circ} \mathrm{E}\right)$ maintains (?) high occurrence from 20 to 03 LT and the peak height distribution is distinctly different between summer and winter. The winter sporadic sodium events are largely confined to altitudes below $96 \mathrm{~km}$, while summer SSLs occurred frequently above $96 \mathrm{~km}$. The simultaneous observations of SSLs, Es and high temperature suggested that the SSLs in subtropical area have a closer link with high temperature conditions than with the formation of Es. The high temperature are most likely caused by gravity wave breaking, together with a newly proposed icy dust sodium reservoir, both processes probably contribute importantly for the formation of subtropical SSLs. In contrast, the ES are 
not essential for most SSLs in the subtropical area, and they seem to influence only a few SSLs above $96 \mathrm{~km}$, especially in the summer months from May to August.

The observations from the Haikou station $\left(19.5^{\circ} \mathrm{N}, 109.1^{\circ} \mathrm{E}\right)$ suggested that the SSLs in low latitude have some similar characteristics with that of the subtropical area. SSLs in Haikou also have stable occurrence frequency between 20-03 LT and the average altitude of the winter SSLs is lower than that of the summer SSLs. However, the occurrence frequency of SSLs above $96 \mathrm{~km}$ does not show any obvious seasonal difference for this station. The abundance of data and observations from low-latitude stations indicate that both the temperature control mechanism and $E_{S}$ theory are likely responsible for the formation of SSLs in the low latitudes and each mechanism can generate distinct types of SSLs. Temperature control mechanism is more likely to account for the large SSLs below $96 \mathrm{~km}$, while ES theory probably contributes more directly to some SSLs above $96 \mathrm{~km}$.

Our results highlighted both the single-mechanism and combined actions of the temperature mechanism and ES theory on the formation of the SSLs in different latitudes and altitudes. The high latitude SSLs have a closer link with the $E_{S}$ theory and the subtropical SSLs correlate more strongly to high temperature, while both the temperature mechanism and $\mathrm{E}_{\mathrm{S}}$ theory probably contribute equally to the SSLs in the low-latitude Haikou station. In fact, we show that the observations in Haikou yield the example that two SSL events could be controlled by different mechanisms even though they occurred at the same location within the same night. 
Key words: sporadic sodium layer, regional character, sporadic E layer, temperature, water vapor, electric field

\section{Introduction}

Sporadic sodium layer (SSL or Nas) is a mesospheric phenomenon in which the density of sodium layer increases very rapidly and could more than double the background value (the enhancement factor, which equals to peak density of the SSL/back ground density of the sodium layer, is greater than 2 ) within a very short time (e.g. within five minute) in a narrow altitude range (Hansen and von Zahn, 1990). SSLs last from tens of minute to several hours (Nagasawa and Abo, 1995; Prasanth et al., 2007), and their full width at half maximum (FWHM) is usually less than $5 \mathrm{~km}$ and sometimes only 12 km (Hansen and von Zahn, 1990; Nagasawa and Abo, 1995; Prasanth et al., 2007). Detected first by Clemesha et al. (1978) (Clemesha et al., 1978), an increasing number of SSLs has been observed in the most recent thirty years. The up-to-date observing stations and related observations of sodium layer over the world are listed in Table 1.

Several mechanisms have been proposed to explain the formation of the SSLs, such as the direct injection of meteors (Clemesha et al., 1988; Clemesha et al., 1980), the bombardments of energetic auroral particles on the dust surface to release free sodium atoms (von Zahn et al., 1987), the recombination of sodium ions from downward sporadic E layers (ES theory) (Collins et al., 2002; Cox and Plane, 1998), and the triggering by high temperature in a local narrow altitude due to the gravity wave breaking (temperature control mechanism) (Zhou and Mathews, 1995; Zhou et al., 
1993). Up to now, however, none of these theories could explain all the observed SSLs (Batista et al., 1991; Clemesha, 1995; Cox et al., 1993; Nesse et al., 2008). A successful mechanism for SSL's formation needs to identify the Na source and explain its rapid release (Cox et al., 1993). Meanwhile, the mechanism needs to explain several characteristic features of SSLs, such as the narrow vertical thickness, the broader horizontal extent, few or rarer occurrences below $90 \mathrm{~km}$, the correlation between SSL and $\mathrm{E}_{\mathrm{S}}$ layer (Nesse et al., 2008), the rare occurrences around $40^{\circ} \mathrm{N}$ (Cox and Plane, 1998), and especially the regional differences of the SSLs, are gradually being highlighted by the increasing number of observations available as listed in Table 1.

The SSLs in different latitudes have significant regional differences in occurrence frequency, seasonal and diurnal distribution, and peak height (Beatty et al., 1988; Clemesha, 1995; Collins et al., 2002; Cox et al., 1993; Daire et al., 2002; Gardner et al., 1995; Zhou and Mathews, 1995; Zhou et al., 1993). For example, the occurrence frequency of SSLs in mid-latitude is much lower than that of the high and low latitude regions (Beatty et al., 1988; Beatty et al., 1989; Clemesha et al., 1988; Cox and Plane, 1998; Fan et al., 2007a; Kirkwood and von Zahn, 1991; Michaille et al., 2001; Rajasekhar and Plane, 1993; Senft et al., 1989; Zhou and Mathews, 1995; Zhou et al., 1993). Meanwhile, high latitude SSLs occur most frequently near the local midnight (Hansen and von Zahn, 1990; Heinrich et al., 2008), but most of low latitude SSLs happen during 2100-2300 LT and 0300-0600 LT (Kwon et al., 1988), with the lowest occurrence at midnight (Prasanth et al., 2007). In addition, the highest occurrence frequency of high latitude SSLs of Northern Hemisphere occurs in summer 
(Heinselman et al., 1998; Nesse et al., 2008), while the maximum occurrence frequency of middle and low latitude SSLs happens in both summer (from May to August) and winter (from January to February) (Dou et al., 2013; Dou et al., 2009; Dou et al., 2010; Prasanth et al., 2007).

The regional differences of occurrence frequency, seasonal and diurnal distribution, and peak height probably indicate the diversity of the formation mechanisms of SSLs in different latitudes (Beatty et al., 1988; Clemesha, 1995; Collins et al., 2002; Cox et al., 1993; Daire et al., 2002; Gardner et al., 1995; Zhou and Mathews, 1995; Zhou et al., 1993). For example, the temperature control mechanism can explain the occurrence of some SSL events in low latitude well (Friedman et al., 2000; Kane et al., 1993; Kwon et al., 1988), but the SSLs in high latitude regions are difficult to be reconciled with the temperature control mechanism (Hansen and von Zahn, 1990; Heinrich et al., 2008; von Zahn and Hansen, 1988). Even at the same location, SSLs in different altitudes or with different characteristic shapes may be caused by distinct mechanisms (Batista et al., 1989; Clemesha, 1990; Collins et al., 2002; Cox and Plane, 1998; Friedman et al., 2000; Hansen and von Zahn, 1990; Kane et al., 1993; Kirkwood and von Zahn, 1991; Mathews et al., 1993). For example, some of the SSLs below 90 $\mathrm{km}$ are probably connected with the meteor trails (Beatty et al., 1988), while some SSLs above $98 \mathrm{~km}$ or $100 \mathrm{~km}$ are closely linked with the Es layers (Gardner et al., 1993; Hansen and von Zahn, 1990; Kane et al., 1993; Yuan et al., 2014).

Overall, with the exception of some satellite observations (Fan et al., 2007a; Fan et al., 2007b; Fussen et al., 2004; Fussen et al., 2010), most of the current studies on the SSLs 
are limited to a single location and the comparative studies of SSLs in different latitudes are scarce. A comprehensive synthesis of SSLs in different latitudes and altitudes is thus needed in order to have a better understanding of the physical processes and formation mechanisms of SSLs. Fortunately, many sodium lidars have been put into operation around the world in the recent decade and provide enough observations for such a synthesis. Although a research of global distributions of SSLs by the Odin satellite showed much greater occurrence in Southern Hemisphere (Fan et al., 2007a), a systematic study in Southern Hemisphere was unavailable due to the lack of long term ground-based lidar observations. So in this study, we summarize and analyze the observed SSLs in Northern Hemisphere with the aim to examine the characteristics and formation mechanisms of SSLs in different latitudes and altitudes. Our efforts emphasize and highlight some new results from the Chinese Meridian Project. This national scientific project aims to measure the near Earth environment along the $120^{\circ} \mathrm{E}$ longitude over China, using the optical, radio and geomagnetic instruments (Wang, 2010). The SSLs from Hefei $\left(31.8^{\circ} \mathrm{N}, 117.3^{\circ} \mathrm{E}\right)$, Wuhan $\left(30.5^{\circ} \mathrm{N}, 114^{\circ} \mathrm{E}\right)$, Haikou $\left(19.5^{\circ} \mathrm{N}, 109.1^{\circ} \mathrm{E}\right)$ and Beijing $\left(40.5^{\circ} \mathrm{N}, 116.0^{\circ} \mathrm{E}\right)$ we described and discussed in this paper are all parts of the Chinese Meridian Project.

\section{Characteristics of high latitude SSLs and possible mechanisms}

The study of SSLs in high latitude and their relationship with other mesosphere parameters started in 1980s, and a large amount of valuable data have been collected in Andenes (Norway, $\left.69^{\circ} \mathrm{N}, 16^{\circ} \mathrm{E}\right)$, Andoya Rocket Range $\left(69^{\circ} \mathrm{N}, 16^{\circ} \mathrm{E}\right)$, and ALOMAR 
(i.e., Arctic Lidar Observatory for Middle Atmosphere Research) facility $\left(69^{\circ} \mathrm{N}, 16^{\circ} \mathrm{E}\right)$

(Hansen and von Zahn, 1990; Heinrich et al., 2008; Nesse et al., 2008; von Zahn and Hansen, 1988).

The early observations highlighted the simultaneous occurrence of SSLs and $\mathrm{E}_{\mathrm{S}}$ in high latitude, pointing to a possible dynamic link between SSLs and ES (Hansen and von Zahn, 1990; von Zahn and Hansen, 1988). Meanwhile, the correlations between high latitude SSLs and aurora were also reported in numerous studies (Collins et al., 1996; Gu et al., 1995; Kirkwood and Collis, 1989; Kirkwood and von Zahn, 1991; Nesse et al., 2008). Based upon these correlations, two possible processes were proposed in 1980s to explain for the formation of high latitude SSLs. First, the collision of energetic aurora particles on dust particles could release free sodium atoms and form the SSLs (von Zahn et al., 1987). Second, the concentrated ions in Es, which can be dragged down to a lower altitude by aurora electric field, could contribute to the formation of SSLs (Kirkwood and von Zahn, 1991; MacDougall and Jayachandran, 2005).

\subsection{Observations of high latitude SSLs}

Early observations of the high latitude SSLs were performed by the sodium lidar at Andenes $\left(69^{\circ} \mathrm{N}, 16^{\circ} \mathrm{E}\right)$ from December 1985 to November 1987 (Hansen and von Zahn, 1990). A total observation time was 378 hours and 75 SSLs were observed with an averaged occurrence of one event per five hours (Hansen and von Zahn, 1990). Most of the SSLs in Andenes took place frequently at 20-01 LT, especially at 21-23 LT 
(Hansen and von Zahn, 1990). No SSLs were detected before 20 LT and after 02 LT throughout the campaign (Hansen and von Zahn, 1990). The average height of SSLs was quite different between summer and winter. Most of the summer SSLs occurred below 97 km (33/40), only a few above 97 km (7/40) and above 100 km (1/40) (Hansen and von Zahn, 1990). In contrast, nearly half of winter SSLs (16/35) were above $97 \mathrm{~km}$ and 13 of them above $100 \mathrm{~km}$ (Hansen and von Zahn, 1990).

From 2001 to 2006, a wind/temperature sodium lidar and ionosonde in ALOMAR operated synchronously and in total 15 summer SSLs and 15 winter SSLs were detected (Heinrich et al., 2008). The details of the SSLs in ALOMAR were shown in Table 2a and $2 \mathrm{~b}$ (Heinrich et al., 2008) and the characteristics of these SSLs are similar to those of the Andenes. For example, significant seasonal differences in height and intensity were also observed in the SSLs of ALOMAR (Table 2a and 2b) (Heinrich et al., 2008). The average height of summer SSLs was $93.8 \mathrm{~km}$, much lower than that of winter SSLs $(102.7 \mathrm{~km})$ (Heinrich et al., 2008). Meanwhile, the average enhancement factor of summer SSLs was much larger than that of winter SSLs (i.e., 6 times in summer vs. 3 times in winter) (Heinrich et al., 2008). The starting time of SSLs in ALOMAR was concentrated in 20-01 LT with noticeable seasonal difference (Heinrich et al., 2008). Most of the summer SSLs happened during 21-01 LT, while most of the winter SSLs occurred during 20-23 LT (Heinrich et al., 2008). Observations were also performed before 20 LT and after 03 LT, but only one SSL was detected in 15-16 LT (Heinrich et al., 2008). The less occurrence of SSLs before 20 LT and after 03 LT in ALOMAR was also consistent with the observations in Andenes which did not detect any SSLs before 
20 LT and after 02 LT from December 1985 to November 1987 (Hansen and von Zahn, 1990).

\subsection{Possible mechanisms for the high latitude SSLs}

Several possible mechanisms, such as the meteor injection, temperature control mechanism and ES theory, have the potential to explain the formation of the SSLs in high latitude regions. However, the increasing observations in recent decades have demonstrated that the meteor injection and temperature control mechanism seemed to be unlikely (Hansen and von Zahn, 1990; Nesse et al., 2008; Østerpart, 2011). For example, there was no one-to-one relationship between the SSLs and meteor injection (Nesse et al., 2008). Meanwhile, since the high latitude SSLs are often observed during the temperature minimum condition (Table 3) (Hansen and von Zahn, 1990; Østerpart, 2011), the temperature control mechanism (Zhou and Mathews, 1995; Zhou et al., 1993) is apparently unsuitable. In the temperature control mechanism, gravity wave breaking is believed to cause temperature rise in a narrow height layer and then release the sodium atoms, but 10 of the 32 observed high latitude SSLs in Andenes are located within a vertical distance of $1 \mathrm{~km}$ from the temperature minimum (Table 3). One SSL observed by ALOMAR wind/temperature lidar on January 26, 2009 was also located at the edge of the sodium layer (Figure 1(a)) and occurred at the temperature minimum (Figure 1(b)) (Østerpart, 2011).

In contrast to the meteor injection and temperature control mechanisms, the $\mathrm{E}_{\mathrm{S}}$ theory for the formation of the SSLs in high latitude has been supported by most of the 
recent observations (Hansen and von Zahn, 1990; Heinrich et al., 2008; Heinselman et al., 1998; Kirkwood and Nilsson, 2000; Kirkwood and von Zahn, 1991; Nesse et al., 2008; von Zahn and Hansen, 1988; Williams et al., 2006). From 1986 to 1987, the simultaneous observations by sodium lidar and ionosonde in Andenes, Norway revealed an obvious link between SSL and Es (von Zahn and Hansen, 1988). Both the beginning time and height of $E_{S}$ were very close to those of the corresponding SSLs (Table 4) (von Zahn and Hansen, 1988).

Figure 2(a) showed the profiles of one SSL (black lines) observed by the wind/temperature lidar at ALOMAR and a descending Es layer (red line) observed by a rocket (Williams et al., 2006). The electron layer occurred about twenty minutes before the onset of the SSL (Williams et al., 2006). Meanwhile, the descending Es layer was located very close to the start altitude of the SSL, with a peak density of $10^{5}$ electron $/ \mathrm{cm}^{-3}, 10$ times greater than that of the SSL (5000 Na atoms $/ \mathrm{cm}^{-3}$ ) (Williams et al., 2006). In addition, the concurrence of the SSL event and $E_{S}$ was also observed on November 11,1997 , at Sondrestrom $\left(66^{\circ} 59^{\prime} \mathrm{N}, 50^{\circ} 57^{\prime} \mathrm{W}\right)$ by the sodium lidar and the nearby VHF radar (Figure 2(b)) (Heinselman et al., 1998). This SSL and the accompanied electron layers occurred nearly at the same time and at the same height (Heinselman et al., 1998). Moreover, observations from the EISCAT incoherent scatter radar in Troms $\varnothing\left(70^{\circ} \mathrm{N}, 19^{\circ} \mathrm{E}\right)$ in northern Norway showed that lower Es between 90 and $100 \mathrm{~km}$ were most frequent in summer (June to August) (Kirkwood, 1997), consistent with the high occurrence of low altitude SSLs in summer (e.g. below $97 \mathrm{~km}$ ) (Hansen and von Zahn, 1990; Heinrich et al., 2008). The increased evidence of direct 
one-to-one concurrence of SSL and $\mathrm{E}_{\mathrm{S}}$, together with the similar seasonal distributions of occurring height, support an important role of $E_{S}$ in the formation of high latitude SSLs.

\subsection{Conclusions for the high latitude SSLs}

The simultaneous observations of the SSLs and $E_{S}$ in high latitude suggest that the SSLs and $E_{S}$ layers have a similar occurrence time and altitude. Statistical results show that most of summer SSLs are located below $97 \mathrm{~km}$, and lower Es between 90 and 100 $\mathrm{km}$ are indeed coincidentally more frequent in summer. Thus ES likely play an important role in the formation of the high latitude SSLs.

\section{Characteristics of subtropical (the latitude range of about $20^{\circ} \mathrm{N} \sim 35^{\circ} \mathrm{N}$ ) SSLs} and possible formation mechanisms

The main SSL observation stations in subtropical area are Hachioji, Tokyo $\left(35.6^{\circ} \mathrm{N}\right.$, $\left.139.4^{\circ} \mathrm{E}\right)$, Shigaraki $\left(34.9^{\circ} \mathrm{N}, 136.1^{\circ} \mathrm{E}\right)$ (Miyagawa et al., 1999; Nagasawa and Abo, 1995), Hefei $\left(31.7^{\circ} \mathrm{N}, 116.3^{\circ} \mathrm{E}\right)$ (Dou et al., 2009; Dou et al., 2010), Wuhan (30.5 $\mathrm{N}$, $114^{\circ}$ E) (Gong et al., 2002; Liu and Yi, 2009; Ma and Yi, 2010; Yi et al., 2013; Yi et al., 2002), Haleakala $\left(20.8^{\circ} \mathrm{N}, 156.2^{\circ} \mathrm{W}\right)$ (Gardner et al., 1995; Qian et al., 1998) and Mauri $\left(20.7^{\circ} \mathrm{N}, 156.3^{\circ} \mathrm{W}\right)(\mathrm{Li}$ et al., 2005). The observation data showed similar characteristics of SSLs between stations in the subtropical area from about $20^{\circ} \mathrm{N}$ to $35^{\circ} \mathrm{N}$ (Cox and Plane, 1998; Miyagawa et al., 1999).

One of the striking features of the subtropical SSLs is the frequent occurrence of 
intense SSLs with large peak densities near $92 \mathrm{~km}$ (Qiu et al., 2015). This kind of SSLs usually lasts for a long period and is accompanied by large temperature increase, likely caused by gravity activities (Gardner et al., 1995; Li et al., 2005; Qian et al., 1998). Meanwhile, the correlations between the subtropical SSLs and $E_{S}$, as indicated by statistical analyses of start time and occurrence altitude, are not as good as those found for events at high latitude (Dou et al., 2009; Gong et al., 2002; Miyagawa et al., 1999).

\subsection{Observations of the SSLs in the subtropical area}

From January 2011 to December 2013, the University of Science and Technology of China (USTC) lidar in Hefei was operated for 1182.15 hours in 158 single nights (parameters of USTC lidar were reported and summarized in Dou et al., (2009)). The SSLs in Hefei were usually defined by the following criteria in the previous studies: the FWHM is less than $5 \mathrm{~km}$, the duration is more than $16 \mathrm{~min}$, and the peak density is at least twice that of the background throughout the whole night (the factor is larger than

2) (Dou et al., 2009). According to this definition, 142 SSLs occasions were identified with an average occurrence frequency of 1 event per 8.3 hours, in accordance with previous reports in the subtropical area (Gong et al., 2002; Michaille et al., 2001; Yi et al., 2002).

Most of the SSLs in Hefei occur from 20 to 03 LT and the occurrence frequency is relatively stable between 20-03 LT (Figure 3(a)). This result is different from observations at high latitude, which have a particular high occurrence frequency at midnight around 24 LT as already reported by Kirkwood and von Zahn (1993). 
The distributions of peak altitudes for the SSLs in Hefei during summer and winter are shown in Figure 3(b), and they are also quite different from those in high latitude. The average peak altitude of the winter SSLs is lower than that of the summer ones. In addition, the altitude for the winter SSLs are seldom above $96 \mathrm{~km}$, while the summer SSLs occur frequently above $96 \mathrm{~km}$.

The details of the 142 SSLs and simultaneous $E_{S}$, as well as high temperatures $(>190 \mathrm{~K})$, are listed in Table 5. The foEs values of $\mathrm{E}_{\mathrm{S}}$ are measured by the nearest ionosonde in Wuhan, and the temperature profiles throughout SSLs are from the SABER database. The link between a SSL and an ES is regarded as 'good' if there is an ES occurrence within 2 hours before the onset of the SSL; otherwise it is considered as 'bad'. A temperature profile is regarded as effective if SABER sweeps Hefei within 2 hours of the onset or the end of the SSLs. The link between a SSL and high temperature is regarded as 'good' if the temperature is higher than $190 \mathrm{~K}$ at the altitude of the SSL according to the effective temperature profile; it is defined as 'bad' if the temperature is lower than $190 \mathrm{~K}$ at the altitude of the SSL.

As shown in Table 5, a total of 96 SSLs events have effective temperature profiles and 81 of them $(84.4 \%)$ have good links with high temperature. However, the correlation between SSLs and high temperature changes with altitude. 14 of $22(63.6 \%)$ SSLs above $96 \mathrm{~km}$ have good links with high temperature, while 67 of 74 (90.5\%) SSLs below 96 km have good links with high temperature (Figure 4(a)).

Although 114 SSLs have effective $E_{S}$ results, only 21 (18.4\%) have good links

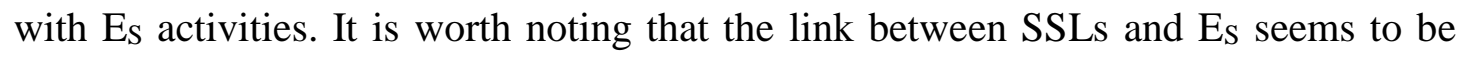


different above and below 96 km. $32.4 \%$ (11 of 34) SSLs above 96 km have good links with Es activities, while only $12.5 \%$ (10 of 80) SSLs below $96 \mathrm{~km}$ have good links with Es activities (Figure 4(a)). Thus the Es activities have substantially more influence on the SSLs above $96 \mathrm{~km}$ than on the SSLs at lower altitude.

The obvious seasonal difference is also observed in the link between SSLs and ES layers (Figure 4(b)). The link between SSLs and $E_{S}$ in summer is $34.8 \%$, which is much stronger than that in other seasons $(7.4 \%)$. One possible explanation for the seasonal difference is the higher occurrence frequency of SSLs above $96 \mathrm{~km}$ in the summer because the SSLs above $96 \mathrm{~km}$ have a closer link with the Es than the SSLs below 96 $\mathrm{km}$. The occurrence frequency of SSLs above $96 \mathrm{~km}$ is $41.7 \%$ in summer, greater than that in other months (19.5\%) (Figure 4(b)).

Similar observations are also made in Wuhan station. A total of 18 SSLs were detected during the simultaneous observation of SSL and $\mathrm{E}_{\mathrm{S}}$ in Wuhan station. 10 of 18 SSLs took place in summer and the other 8 in other seasons. 7 of 10 summer SSLs have good links with Es, while only 3 of 8 SSLs in other seasons do so (Gong et al., 2002). Meanwhile, out of the 7 summer SSLs linked with $E_{S}, 5$ have peak altitudes above 96 km (Gong et al., 2002).

\subsection{Possible mechanisms for the subtropical SSLs}

The weak link between SSLs and ES at Hefei station essentially rules out the role of ES as a direct source of sodium for most of the observed SSLs. As discussed in section 3.1, the subtropical SSLs occur frequently in the temperature maximum regions, especially 
for the SSLs below $96 \mathrm{~km}$, which have a good link (90.5\%) with high temperatures. Thus the temperature control mechanism seems to be applicable for the subtropical SSLs.

According to the temperature control mechanism, a gravity wave, breaking at the mesopause, would dump its energy into a narrow altitude region and sharply increase the local temperature (Zhou and Mathews, 1995; Zhou et al., 1993). The increased temperature would then trigger the release of sodium atoms from a pre-exiting sodium reservoir (Zhou and Mathews, 1995; Zhou et al., 1993).

The temperature control mechanism assumes a pre-existing sodium reservoir. Some studies discussed and examined this issue in details but the questions are largely unresolved (Gardner et al., 1995). Based on the simultaneous observations of sodium lidar, wind/temperature lidar and airborne satellites, Qiu et al., (2015) proposed a new possibility that the sub-visible icy dust particles could efficiently absorb enough sodium atoms on their surface to form a sodium film to serve as a sodium reservoir (Qiu et al., 2015). A detailed possible mechanism for the subtropical SSLs was correspondingly presented (Qiu et al., 2015): First, under the extremely cold temperatures, icy dust particles scavenge a large quantity of sodium atoms on the surface as a solid sodium film. Second, the ice surface would sublimate under warm weather to leave the residual sodium film. Last, under the sharply elevated temperature caused by the gravity wave breaking, the sodium film releases free sodium atoms to form a SSL.

This new hypothesis for the formation of the subtropical SSLs is strongly supported by the observations in Hefei station. For example, out of the total 61 typical 
SSL events observed at the Hefei station, 57 (with a rate of $93.4 \%$ ) underwent extremely low temperatures below $150 \mathrm{~K}$, sometimes even as low as only $118 \mathrm{~K}$, within three days before the onset of the SSLs. The water vapor concentrations in the mesopause region near $93 \mathrm{~km}$ often showed a sharp decline before the SSLs and returned to normal level after the SSLs. The extremely low temperatures and sharp decreases of water vapor together implied the possible growth of sub-visible icy dust particles. The temperature profiles during these SSLs showed that 40 among 47 SSLs (with a rate of $85.1 \%$ ) with effective temperature profiles occurred in the temperature maximum regions over $190 \mathrm{~K}$. The high temperatures (often exceeding $200 \mathrm{~K}$ ) during the SSLs and the return of water vapor to the pre-SSLs level implied a destruction of the sodium reservoir.

\section{Case studies}

Typical case 1: a SSL on November 2, 2007, detected by both USTC and WIPM lidars

On November 2, 2007, a typical SSL was observed by both the USTC lidar $\left(31.8^{\circ} \mathrm{N}, 117.3^{\circ} \mathrm{E}\right)$ and WIPM (Wuhan Institute of Physics and Mathematics) lidar $\left(30.5^{\circ} \mathrm{N}, 114.4^{\circ} \mathrm{E}\right.$, see Gong et al, 2002 for details about this lidar) (Figure 5). As recorded by the USTC lidar, this SSL had a duration from 01:36 LT to 04:48 LT, a peak density of $17242 \mathrm{~cm}^{-3}$ and an altitude of $92.1 \mathrm{~km}$. The observations by the WIPM lidar are consistent with those by the USTC lidar (Dou et al., 2009).

On October 31, two days before this large SSL, extremely low temperatures were 
detected by SABER (Figure 6(a)). One temperature minimum was $146 \mathrm{~K}$ at $99 \mathrm{~km}$ at 07:48 UT (15:48 LT, LT=UT+8) (blue scatters), and $131 \mathrm{~K}$ at $102 \mathrm{~km}$ at 18:33 UT (02:33LT on November 1) (red scatters). The water vapor content decreased sharply on November 1, one day before the SSL, and returned to the normal level on November 3 and November 4 (Figure 6(b)).

The extremely low temperatures on October 31 and November 1 and the sharp decrease of water vapor content before the SSL imply that a large quantity of water vapor may coagulate to form the icy dust particles. The icy surface could collect a large number of sodium atoms (e.g., more than $10^{4} \mathrm{~cm}^{-3}$ ). On November 3 and November 4 , after the SSL, the water vapor concentration returns back to normal level, implying the possible evaporation of the sub-visible icy dust.

The temperature profile from SABER at 17:11 UT on November 2 (at 1:11 LT on November 3) was shown in Figure 7(a). The sampling time was close to the onset time of the large SSL at 01:36 LT. The temperature maximum region was from 92 to $94 \mathrm{~km}$, with a peak temperature of $222 \mathrm{~K}$ at $92.0 \mathrm{~km}$. Both the temperature maximum region and the peak altitude coincided with the SSL's well.

These observations are consistent with the temperature control mechanism proposed by (Zhou and Mathews, 1995; Zhou et al., 1993) and also consistent with our sub-visible icy particles sodium reservoir hypothesis. In order to test whether this SSL was triggered by elevated temperature due to gravity wave breaking, the profile of sodium atom density throughout the whole progress of the SSL is shown in Figure 8(a). The bursts of the sodium atoms for this event observed by the Wuhan University lidar 
system (WU lidar; this is a second lidar in operation in Wuhan; the other one being the WIPM lidar) using a sampling time of $8 \mathrm{sec}$ is shown in Figure $8(\mathrm{~b})$. The pulse period of sodium atoms was about $30 \mathrm{sec}$ with a density of $5000 \mathrm{~cm}^{-3}$ (Liu and Yi, 2009).

For a gravity wave, the following equations describe the relationship between wavelength ( ), wave velocity ( ) and period $(T)$ :

$$
\begin{array}{r}
=\frac{}{T}, \\
T=\frac{\lambda}{v}=\frac{1}{f}=\frac{1}{2 \pi \omega},
\end{array}
$$

According to Zhou and Mathews (1995), for a gravity wave with an angular frequency of $\omega$, the heating rate at breaking is $\omega^{\prime}=40 \omega$ (Zhou and Mathews, 1995), so the heating period will be $T^{\prime}=\frac{1}{40} T=\frac{1}{40} \cdot \frac{\lambda}{v}$

When the gravity wave breaks, $v \approx 3.63 \lambda, \lambda$ has at the unit of $\mathrm{km}, \quad v \mathrm{~m} / \mathrm{s}$ (Zhou and Mathews, 1995), so the heating period will be $T^{\prime}=34.4 \mathrm{~s}$, about half a minute, in excellent agreement with the burst period observed by WU lidar (about $30 \mathrm{sec}$, Figure 8(b)). Thus the observed SSL on November 2 supports the hypothesis that the fast increasing temperature from gravity wave breaking could trigger the release of sodium atoms from a pre-existing sodium reservoir.

Furthermore, before the onset of the SSL at 01:36 UT, the $\mathrm{E}_{\mathrm{S}}$ were not active. The foEs variation profile, as measured by the COSMIC satellite on this night, revealed only one peak at 22 LT near Hefei (Figure 7(b)), more than 3 hours before the SSL, and the foE $E_{S}$ of the $E_{S}$ had a normal peak value of $4 \mathrm{MHz}$ (Dou et al., 2009). Thus, this large SSL event was unlikely caused by Es activity. 


\section{Typical case 2: a SSL on May 13, 2013, observed by both USTC and WIPM lidars}

On May 13, 2013, another large SSL was observed by USTC sodium lidar and USTC wind/temperature lidar at Hefei. The nearby WIPM lidar at Wuhan also recorded this event. The contour images of the sodium density observed by the three lidars were shown in Figure 9. As observed by the USTC lidar, the complete process of the SSL lasted from 16:55 UT to 19:13 UT, and the peak density was $4300 \mathrm{~cm}^{-3}$ (with $\mathrm{f}=3.5$ ) at $94.7 \mathrm{~km}$ at 17:16 UT. The peak altitude observed by WIPM lidar was $91.8 \mathrm{~km}$ at 18:14 UT. The SSL observed by both stations was believed to be the same event since the shapes of them were similar.

The observed temperature profiles showed a cold phase from 12 UT to 15 UT between 92 and $96 \mathrm{~km}$ altitude, and a hot phase from 17 to 19 UT between 92 and $98 \mathrm{~km}$ (Figure 10(a) and 10(b)). The mesopause went through extremely cold weather below $160 \mathrm{~K}$ for several hours before the onset of the SSL. The low temperature, with a minimum of $142 \mathrm{~K}$, indicated a possibility for the generation of icy dust sodium reservoir. Sodium species might be gathered during this cold phase. From about 16:00 UT, temperature increased more than $50 \mathrm{~K}$ within 10 minutes, and both the duration and location of temperature enhancement were in accord to the SSL. The observed overlap of temperature and sodium density suggested that the triggering of this SSL event was related to the temperature enhancement.

On the other hand, $\mathrm{E}_{\mathrm{S}}$ were not active on May 13 according to Wuhan ionosonde, with no Es echoes detected during the 4 hours before the SSL event. The rareness of ES 
indicated that the sodium atoms were not recombined from the sodium ions locally. This result is consistent with our previous studies which suggested that SSLs in this area usually had weak correlation to Es (Qiu et al., 2015).

Similar to the observations of this SSL event, the synchronous changes of the wind shear, temperature variation and SSL event was also observed by Mauri station on October 10, 2003 (Li et al., 2005). The progress of gravity wave's breaking down into ripples was also observed at the same time by the Mauri $\mathrm{OH}$ imager (Li et al., 2005). These researchers regarded this kind of variations in sodium density an indicator of overturning in potential temperature and gravity wave breaking (Li et al., 2005).

\subsection{Conclusions for subtropical SSLs}

The temperature control theory is the most likely mechanism for explaining the close relationship between high temperature and the subtropical SSLs, the occurrence of extremely low temperatures several days before SSLs, the variations of water vapor concentrations throughout SSLs, and the simultaneous wind shear, temperature enhancements and gravity wave activities. The gravity wave breaking heats a narrow altitude range and triggers a pre-existing sodium reservoir to release sodium atoms rapidly. The heating frequency deduced from the gravity wave theory is consistent with the small scale bursts of sodium density observed by WU lidar. The qualified sodium reservoir is likely formed from sub-visible icy dust particles, which could efficiently absorb sodium atoms on the ice surface and form a sodium film. The $E_{S}$ are not essential for most SSLs in the subtropical area, and they seem to influence only some SSLs above 
$96 \mathrm{~km}$, especially in the summer months (from May to August).

\section{Characteristics of low latitudes (below $20^{\circ} \mathrm{N}$ to the equator) SSLs and possible formation mechanism}

The SSLs in low latitudes (i.e., about $20^{\circ} \mathrm{N}-20^{\circ} \mathrm{S}$ ) have also been observed by the stations from Hawaii, Haikou, Brazil, and so on. The results suggested a link between the low latitudes SSLs and the $E_{S}$, temperature, tide, and so on. For example, the observations during AIDA-89 showed that the SSLs between altitudes of $93 \mathrm{~km}$ and 97 $\mathrm{km}$ at Arecibo $\left(18^{\circ} \mathrm{N}\right)$ was closely linked with the Es layer and thus the ES likely played an important role in the formation of these SSLs (Kane et al., 1993). However, the $\mathrm{E}_{S}$ layer was not supposed to provide enough sodium source for these SSLs (Kane et al., 1993). Instead, the dust particles or aerosols probably provide the sodium reservoir for the SSLs between $93 \mathrm{~km}$ and $97 \mathrm{~km}$ at Arecibo (Kane et al., 1993).

It is worth noting that two minor SSLs, occurred much higher at $101 \mathrm{~km}$ and 107 $\mathrm{km}$ at Arecibo, were accompanied by $\mathrm{E}_{\mathrm{S}}$, and they were likely generated directly from the $E_{S}$ layers since the electron density was 100 times of the peak sodium density (Kane et al., 1993). The direct link between Es and SSLs above 97 was also supported by the observation of Coqui-2 rocket campaign which showed that the SSLs above $97 \mathrm{~km}$ were always accompanied by ion layers and those below $97 \mathrm{~km}$ usually occurred alone (Friedman et al., 2000). In addition, the results by Beatty et al. (1989), Shibata et al. (2006) and Sridharan et al. (2009) in low latitudes also provided additional evidences to the direct link between Es and SSLs above 97 in low latitudes (Beatty et al., 1989; 
Shibata et al., 2006; Sridharan et al., 2009). Overall, the coincidence between electron/ion layer and the peaks of the SSL above $97 \mathrm{~km}$ in low latitude are supported by increasing number of observations, implying that the $E_{S}$ layer is likely the direct source for the formation of these high altitude SSLs (Friedman et al., 2000; Kane et al., 1993).

In addition to the connection with $\mathrm{E}_{\mathrm{S}}$, gravity wave, high temperature and tides were also proposed to explain some of these low-latitude SSLs. For example, an SSL event at $95 \mathrm{~km}$ at Arecibo was observed during a gravity wave propagation through 94$97 \mathrm{~km}$ regions (Hecht et al., 1993). Based on the link between SSLs at Arecibo and temperature enhancement from variations of $\mathrm{O}_{2}(0,1)$ rotation temperature, Zhou et al. (1993) and Zhou and Mathews (1995) proposed the temperature control mechanism that the SSLs were triggered from dust reservoir by heating due to gravity wave breaking (Zhou and Mathews, 1995; Zhou et al., 1993). In addition, Kwon et al. (1988) suggested the involvement of tides in the formation of SSLs in Mauna Kea $\left(19^{\circ} 50^{\prime} \mathrm{N}\right.$, $\left.155^{\circ} 28^{\prime} \mathrm{W}\right)$ (Kwon et al., 1988).

\subsection{Observations of SSLs in a low latitude station of Haikou $\left(19.5^{\circ} \mathrm{N}, 109^{\circ} \mathrm{E}\right)$}

From January 2011 to December 2013, the Haikou sodium lidar operated for 1063.31 hours in total, and 186 SSL occasions were detected, with an average occurrence of 1 event/ 5.7 hrs. The distributions of the onset time of these SSLs were shown in Figure 11(a) and the result suggested that the low latitude SSLs in Haikou did not have obvious maximum frequency near mid night (24:00 LT) (Figure 11(a)), similar 
to that of Hefei station but different from that of the high latitude situations,

In general, the seasonal distribution of the peak altitudes of the SSLs in Haikou is similar to that of the subtropical SSLs, with a lower altitude for winter SSLs and higher altitude for summer SSLs (Figure 11(b)). However, the occurrence frequency of SSLs above $96 \mathrm{~km}$ in Haikou is nearly the same in summer and in winter, which is different from the SSLs in subtropical area.

The links between the 186 SSL occasions and $\mathrm{E}_{\mathrm{S}}$ are listed in Table 6. Out of the 186 SSLs, 158 SSLs (with a rate of $85 \%$ ) had efficient Es observations and 79 SSLs (with a rate of $50.0 \%$ ) had a good link with Es. 120 SSLs (with a rate of $64 \%$ ) had efficient temperature profiles, and 81 SSLs (with a rate of $67.5 \%$ ) had a good link with high temperatures. These results suggested roughly equal influences of ES layers and high temperatures on the SSLs in Haikou station. However, the differences were also observed in the links between SSLs, $\mathrm{E}_{\mathrm{S}}$ and high temperature in different altitudes. About $63.4 \%$ (33/52) of SSLs above $96 \mathrm{~km}$ have good links with the Es, but only $43.3 \%$ (46/106) of SSLs below $96 \mathrm{~km}$ do so (Figure 12). In contrast, $55.3 \%$ of SSLs above 96 km have good links with high temperature, while $73.2 \%$ of SSLs below $96 \mathrm{~km}$ do so (Figure 12). These distributions indicated that the SSLs above $96 \mathrm{~km}$ have a closer links with the Es than those of below $96 \mathrm{~km}$, but the SSLs below $96 \mathrm{~km}$ have a closer links with the high temperature. These results also showed a much stronger link between SSLs and Es in Haikou than that in Hefei, especially for the SSLs above $96 \mathrm{~km}$.

\subsection{Possible mechanism for the formation of low latitude SSLS}


From January 17 to 22,1987 , the sodium lidar at Mauna Kea, Hawaii (1950'N, $155^{\circ} 28^{\prime} \mathrm{W}$ ) operated for 30 hours in total, and 16 SSLs were detected with an occurrence frequency of 1 event/1.9 hrs (Kwon et al., 1988). In these SSLs, 7 of 16 happened above $96 \mathrm{~km}$ and $85.7 \%$ of them (6/7) were connected with Es. However, for the SSLs below $96 \mathrm{~km}$, only $22.2 \%$ of them (2/9) were accompanied by ES (Kwon et al., 1988). These results suggested a closer connection between SSLs and $E_{S}$ at a higher altitude.

Similar to those at Mauna Kea, the observations at Arecibo Observatory $\left(18^{\circ} \mathrm{N}\right.$, $67^{\circ} \mathrm{W}$ ) also showed that the SSLs above $97 \mathrm{~km}$ were closely related to Es (Friedman et al., 2000; Kane et al., 1993). From February to April 1998, the sodium lidar at Arecibo together with rockets observed 15 SSLs occasions, with 6 events above 100 $\mathrm{km}$ and 8 events below $98 \mathrm{~km}$ (Friedman et al., 2000). 6/6 (100\%) of the events above $100 \mathrm{~km}$ were accompanied by ES and 2/8 (25\%) of the SSLs below $98 \mathrm{~km}$ were related to $E_{S}$ (Friedman et al., 2000). The SSLs between $93 \mathrm{~km}$ and $97 \mathrm{~km}$ observed on January, March and April, 1989 had a similar peak density to that of the Es, but the phase of the increasing sodium density was different from that of the ES (Kane et al., 1993). Thus these SSLs between $93 \mathrm{~km}$ and $97 \mathrm{~km}$ were unlikely to be originated from $\mathrm{E}_{\mathrm{S}}$ directly (Kane et al., 1993). In contrast, the high altitude SSLs have the possibility to be directly generated from the ES (Kane et al., 1993). For example, two minor SSLs at $101 \mathrm{~km}$ and $107 \mathrm{~km}$ had the same peak altitudes as the Es and these two SSLs had the same phase of density increase with the ES (Kane et al., 1993). Meanwhile, the electron density of $E_{S}$ was about 100 times more than the sodium atom density of the SSLs and thus the $E_{S}$ could provide enough sodium ions to form these two high altitude SSLs. In addition to 
the observations at Mauna Kea and Arecibo, the coincidence between high altitude SSLs and Es were also detected by many other campaigns at low latitude (Beatty et al., 1989; Mathews et al., 1993).

The observations at Arecibo showed that the low latitude SSLs had a close relationship with high temperatures (Zhou and Mathews, 1995; Zhou et al., 1993). Zhou et al. (1993) observed the correspondence between temperature enhancement and sodium density increase for the SSLs at Arecibo (Zhou et al., 1993). They proposed that in the gravity wave breaking regions large quantity of energy would be poured into a narrow altitude range to trigger the release of sodium atoms from a sodium reservoir, which are most likely made of dust particles (Zhou et al., 1993). The later studies by Zhou and Mathews (1995) also supported that the SSLs in low latitude were probably related to gravity wave breaking (Zhou and Mathews, 1995). In addition, the large SSLs were also observed in the regions of dissipating gravity wave between 94 and $97 \mathrm{~km}$ by Hecht et al. (1993). These results implied that some SSLs at low latitude could also be triggered from sodium reservoir by the gravity wave breaking (Hecht et al., 1993).

In summary, both $\mathrm{E}_{\mathrm{S}}$ and high temperature influence the formation of SSLs at low latitude area. The sodium ions in the Es likely contribute to the high altitude SSLs directly, while high temperature caused by gravity wave activities is probably connected with large SSLs in lower altitude.

\section{Case studies}

Typical case 1: a SSL on June 28, 2013 at Haikou station 
On June 28, 2013, the Haikou sodium lidar observed a SSL event starting at 19:01 UT at a high peak altitude of $97.7 \mathrm{~km}$ (Figure 13(a)). The SSL reached its peak density of $3888.0 \mathrm{~cm}^{-3}$ at 19:40 UT (Figure 13(b)), with a factor of 2.7 and FWHM of $3.0 \mathrm{~km}$. Note that the lidar observation of this SSL halted 34 minutes between 19:06 and 19:40 due to the bad weather (Figure 13(a)).

The temperature profile at 18:08 UT from SABER showed that the SSL occurred near the temperature minimum and the temperature of the peak altitude, $97.7 \mathrm{~km}$, was only $159 \mathrm{~K}$ (Figure 14(a)). Thus this SSL was difficult to be explained by the temperature control mechanism.

The VHF radar and the ionosonde nearby also operated on June 28, 2013 and both of them observed obvious ionosphere disturbances during this SSL (Figure 14(b) and 14(c)). The ionosonde recorded two successions of downward Es and the SSL during the downward propagation of the second succession (Figure 14(b)). The observed foE values reached 5.17 MHz, the largest value between 05:55 UT and 22:25 UT, at 18:45 UT, about 16 minutes before the onset of the SSL. Figure 14(c) shows the activities of the plasma irregularities observed by the VHF radar during this SSL event. The irregularities were obvious at 18:00 UT (light gray scatter) and 20:00 UT (dark gray scatter), in coincidence with the SSL event, which started at 19:01 UT. The plasma irregularities vanished at 22:00 UT, about one hour after the SSL event (Figure 14(d)). The ionosonde observation, together with the VHF radar result, presented a clear correlation between the SSL and the irregularities of the ionosphere. Thus the $\mathrm{E}_{\mathrm{S}}$ activities are likely the direct source of this SSL event. According to the Es combination 
theory, the sodium atoms could be formed directly from the following chemical reaction:

$$
\mathrm{Na}^{+} \cdot \mathrm{X}+e^{-} \rightarrow \mathrm{Na}+\mathrm{X}\left(\mathrm{X}=\mathrm{O}, \mathrm{N}_{2}, \mathrm{CO}_{2}, \mathrm{H}_{2} \mathrm{O}\right)
$$

(Collins et al., 2002; Cox and Plane, 1998; Daire et al., 2002),

The chemical reaction rate (v) for this second-order reaction could be calculated using the following equation:

$$
v=k\left[N a^{+} \times X\right] N_{e},
$$

The reaction rate coefficient $\mathrm{k}$ for the chemical reaction is defined as

$$
k=1 \times 10^{-6} \sqrt{\frac{200}{T}}
$$

(Collins et al., 2002; Cox and Plane, 1998; Daire et al., 2002), and the electron density $N_{e}$ could be calculated using the following equation:

$$
N_{e}=1.24 \times 10^{4} \mathrm{foE}_{S}{ }^{2}\left(\mathrm{~cm}^{-3}\right)
$$

(Williams et al., 2007),

To calculate the chemical reaction rate, we assumed a concentration of $100 \mathrm{~cm}^{-3}$ for $\left[\mathrm{Na}^{+} \cdot \mathrm{X}\right]$ (Daire et al., 2002) and used the observed value of $5.17 \mathrm{MHz}$ for foEs, and $159 \mathrm{~K}$ for $\mathrm{T}$. The calculated rate is $v=3.1$ sodium atoms $\mathrm{cm}^{-3} \mathrm{~s}^{-1}$, close to the required source strength of sodium atoms of 3 sodium atoms $\mathrm{cm}^{-3} \mathrm{~s}^{-1}$ for the formation of SSL (Cox et al., 1993).

The sodium density variation profile of this SSL was different from those of typical large SSLs observed by lidars at both Hefei and Wuhan on November 2, 2007 and May 13, 2013 (see section 3.1 and 3.2 for the details of these two SSLs). Throughout the whole process of this SSL, sodium density did not increase; instead, sodium density 
decreased during the last 100 minutes. These results were different from the pulsed form of the two SSLs cases at Hefei, which were probably caused by the gravity wave breaking. In contrast, the recombination of sodium ions in the Es could be a possible candidate for mechanism of this SSL.

\section{Typical case 2: a SSL on November 9, 2012 at Haikou station}

However, some SSLs in Haikou have good links with high temperatures. On November 9, 2011, a typical SSL event lasting about 2 hours was observed by the Haikou sodium lidar (Figure 15(a)). This SSL reached its peak density of $5562.70 \mathrm{~cm}^{-}$ ${ }^{3}$ at $90 \mathrm{~km}$ at 17:52 UT, with a factor of 4.2 and FWHW of $2.1 \mathrm{~km}$ (Figure 15(b)). The characteristics of this low latitude SSL, such as the peak altitude, the shape of the peak density profile and the pulse enhancements of sodium atoms, are similar to those of the typical subtropical cases on November 2, 2007 and May 13, 2013, observed by both the USTC and WIPM lidars. For example, the incremental image for the sodium atom density was shown in Figure 15(c) and the violent sodium density enhancement was observed throughout this SSL event.

The variation profiles of temperatures before this SSL event and water vapor concentrations before and after this SSL were also similar to those of the cases on November 2, 2007 and May 13, 2013 in the subtropical area. For example, extremely low temperatures were observed before this SSL, as low as $145 \mathrm{~K}$ on November 6 and $134 \mathrm{~K}$ on November 8 (Figure 16(a)). The water vapor concentration decreased sharply one day before this SSL and returned to a high level after the SSL (Figure 16(b)). The 
similar characteristics between this SSL and the SSLs in subtropical area, together with the variation profiles of temperatures and water vapor, implied that the icy dust reservoir model might also be suitable for some SSLs in the low latitude region.

The temperature profiles at 16:10 UT and 16:11 UT, near the time of the peak density, supported the temperature control mechanism. Temperatures in the region of 89 to $93 \mathrm{~km}$ exceeded $200 \mathrm{~K}$, with a maximum value of $223 \mathrm{~K}$ at $91.7 \mathrm{~km}$ (Figure 16(c)). The region of the high temperature area and the maximum temperature location corresponded well with those of the SSL.

Furthermore, there was no Es signal observed from 0:00 UT to 21:00 UT on September 9 by the ionosonde in Haikou. Thus it is unlikely that this SSL originated directly from the $E_{S}$.

\section{Typical case 3: a SSL on August 31, 2011 at Haikou station}

The observations in Haikou also showed that two SSL events could be controlled by different mechanisms even though they occurred at the same location during the same night. One example was observed on August 31, 2011 and shown in Figure 17(a). SSL1 peaked at $99.1 \mathrm{~km}$ with a peak density of $1458.1 \mathrm{~cm}^{-3}$ at 22:44 LT (14:44 UT) (Figure 17(c)) and SSL-2 reached its peak density at 0:27 LT (16:27 UT) at $90.6 \mathrm{~km}$ with a maximum sodium density of $3975.9 \mathrm{~cm}^{-3}$ (Figure 17(d)). The peak shapes of the two SSLs were quite different: the peak of SSL-1 was located on the edge of the main sodium layer with a wide extent and SSL-2 peaked at the centroid of the sodium layer with a much narrower width (Figure 17(c) and 17(d)). SSL-1 started from 22:20 UT 
and lasted only thirty minute while SSL-2 began at 22:50 UT and persisted for more than 4 hours.

The ES layers occurred frequently within two hours before SSL-1, but they were absent during the long period of SSL-2 (Figure 18(b)). SSL-1 occurred during a fast downward propagation of a succession of $E_{S}$ (black scatters in Figure 18(b)), consistent with the prediction of $E_{S}$ theory. The results from the VHF radar showed that the ionosphere was active within two hours before SSL-1. The VHF radar detected irregularities of SSL-1 at 14 UT (Figure 18(c)), but the irregularity almost disappeared at 18 UT (Figure 18(d)) when SSL-2 was still active with enhanced sodium atoms (Figure 17(b)). Thus, it is unlikely that the sodium ions in the $E_{S}$ could maintain for such a long time bursts of great amount of sodium atoms throughout the whole progress of SSL-2.

The temperature records from SABER for this night at 17:08 UT (01:08 LT) and 17:09 UT (01:09 LT) were shown in Figure 18(a). The sampling time was near one hour before the peak time of SSL-2, when the sodium density was still in a rapid growth stage. The temperature profiles showed a maximum over $200 \mathrm{~K}$ in the region between 89.7 and $93.8 \mathrm{~km}$, matching with the SSL range very well. Meanwhile, a peak value of $214 \mathrm{~K}$ occurred at $92.3 \mathrm{~km}$, near this SSL's peak altitude of $90.6 \mathrm{~km}$. In addition, the altitude and shape of SSL-2 were very similar to those of the SSLs observed on November 2, 2007 and December 24, 2011 in Hefei and on November 9, 2012 in Haikou. The temperature profile of SSL-2 was in accord with those of other three typical large SSLs. So SSL-2 on August 31, 2011 at Haikou station was likely to be 
formed by the temperature control mechanism.

\subsection{Conclusions for the low latitude SSLs}

The abundant observations indicate that both the temperature control mechanism and ES theory are likely responsible for the formation of SSLs in the low latitudes and generate distinct types of SSLs. Temperature control mechanism is more likely to account for the large SSLs below $96 \mathrm{~km}$, while $\mathrm{E}_{\mathrm{S}}$ theory probably contributes to the small SSLs above $96 \mathrm{~km}$.

\section{Discussions}

The available observations from China and elsewhere suggested that the SSLs in different latitudes have distinct regional characteristics, such as the occurrence time and frequency. The different characteristics, together with the diversity of the connections between the SSLs and $\mathrm{E}_{S} /$ high temperatures, indicated that there are probably several types of the SSLs and they may have different formation mechanisms.

\subsection{Particular mechanism for High latitude SSLs: the $E_{S}$ theory}

Observations from a high latitude station, Andenes $\left(69^{\circ} \mathrm{N}\right)$, showed that 15 out of 16 SSLs were located below $96 \mathrm{~km}$ in summer, with 13 below $95 \mathrm{~km}$ (Table 2a) (Heinrich et al., 2008). But in the non-summer months, 14 out of 15 SSLs occurred above 98 km, including 13 above $101 \mathrm{~km}$ (Table 2b) (Heinrich et al., 2008). These results were similar to those reported by Hansen and von Zahn (1990) (Hansen and von 
Zahn, 1990). In high latitude, SSLs were often accompanied by $E_{S}$ layers. SSLs and $E_{S}$ had a similar time and altitude of occurrences, and thus SSLs in high latitudes were likely originated directly from Es (Heinselman et al., 1998; Williams et al., 2006).

Studies of the polar $E_{S}$ by MacDougall et al (2000a; 2000b) revealed that the $E_{S}$ in summer time of Northern Hemisphere had characteristics of narrow peak, long duration and low-altitude location (occurring at the bottom of the ionosphere E layer), but in winter the $E_{S}$ had a broader peak, shorter duration and high-altitude location (occurring in the middle and upper part of the E layer) (MacDougall et al., 2000a; MacDougall et al., 2000b). The formation of Es was likely controlled by gravity wave, which could drag metal and nonmetallic ions from ionosphere F layer down to E layer and converge them at the turning point of the vertical motion (MacDougall et al., 2000a; MacDougall et al., 2000b). In summer, this transient layer persists for a longer time due to the long-lived metallic ions maintained in an ionized state by charge exchange of neutral metal atoms with the ambient $\mathrm{E}$ region $\mathrm{NO}^{+}$and $\mathrm{O}_{2}{ }^{+}$ions produced by photoionization (MacDougall et al., 2000a).

Further studies showed that the height distributions of high latitude $E_{S}$ could also be controlled by the directions of electric fields (Kirkwood, 1997). Near the North Pole, ES in summer were influenced by the southward electric fields, leading to thin shape, strong intensity, long lifetime and lower height; but in winter, the influence was mainly from gravity waves or tides, leading to a weak intensity, higher altitude, and shorter duration of the $E_{S}$ (Kirkwood and Nilsson, 2000). High latitude $E_{S}$ layers had a maximum frequency near or prior to local midnight (Kirkwood and Nilsson, 2000). 
These characteristics of $\mathrm{E}_{\mathrm{S}}$ were apparently similar to those of the high latitude SSLs; both ES and SSLs had a low location and strong intensity in summer and a maximum frequency within 2 hours before local midnight. Most low altitude Es below $100 \mathrm{~km}$ were accompanied by southward electric field, but high $E_{S}$ between 100 and $110 \mathrm{~km}$ were often accompanied by northward electric field or no electric field (Kirkwood, 1997). However, ES layers above $110 \mathrm{~km}$ were seldom accompanied by southward electric field (Kirkwood, 1997). Therefore, the low altitude $E_{S}$ layers were probably mainly controlled by southward electric field (Figure 19), and the high altitude Es by northward electric field. The relationship between southward electric field and low altitude sporadic Fe layers was observed by Kirkwood and Zahn (1993) during the METAL Campaign near $69^{\circ} \mathrm{N}$ (Table 7), showing that all the Fes below $96 \mathrm{~km}$ were accompanied by southward electric field (Kirkwood and von Zahn, 1993).

The summer $E_{S}$ layers in high latitude were located very low due to the southward electric field, and at the same time SSLs also started at a low altitude. Kirkwood (1997) showed that $80 \%$ of the high latitude summer Es was below $100 \mathrm{~km}$, and this phenomenon was regarded as the main reason for the low altitude SSLs in the summertime (Kirkwood, 1997). But the situations in mid and low latitude were quite different, as $E_{S}$ layers in these regions were mainly controlled by tides and gravity waves with very weak influence of electric field (Kirkwood and Nilsson, 2000). The distributions of the onset time of high latitude SSLs were also shown by Kirkwood (1997). Total $\mathrm{E}_{\mathrm{S}}$, including those between 90 and $100 \mathrm{~km}$, between 100 and $110 \mathrm{~km}$ and above $110 \mathrm{~km}$, occurred most frequently in the period from 21 LT to 23 LT (Kirkwood, 
1997). The occurrence time distributions of $E_{S}$ were in good accord with that of SSLs (Hansen and von Zahn, 1990; Heinrich et al., 2008). MacDougall and Jayachandran (2005) made a similar conclusion that Es layers in the northern cusp latitudes had a maximum frequency in the midnight, likely due to the convergence of ionizing from the electric field during the afternoon convection reversal (MacDougall et al., 2000a).

The seasonal frequency distributions of Es layers were suggested to be influenced by solar Activities (MacDougall et al., 2000a; MacDougall et al., 2000b). In winter, positive ions would recombine with electrons fast, leading to a very short lifespan of the ions (MacDougall et al., 2000a; MacDougall et al., 2000b). But in summer, the intense solar photoionization could greatly increase the ion densities of $\mathrm{NO}^{+}$and $\mathrm{O}_{2}{ }^{+}$ and decrease the efficiency of recombination of metal ions (MacDougall et al., 2000a; MacDougall et al., 2000b). Thus in the summertime metal ions could last for a long time, resulting in a larger frequency, stronger intensity and longer duration of the $\mathrm{E}_{\mathrm{S}}$ layers (MacDougall et al., 2000a; MacDougall et al., 2000b).

Due to the same seasonal distributions of the high latitude SSLs and Es, the simultaneous onset time of the maximum frequency and the similar occurrence altitude, the ES layers were very likely to be the direct source of the SSLs in high latitude. In addition, the observed correlations between SSLs, ES and auroral activities also can be reconciled by this mechanism because the ES layers were also influenced by electric field which was likely produced by aurora.

However, the situation would be different at middle and low latitudes, where the impact of auroral activities was much less. It was not easy for the mid and low latitude 
$E_{S}$ layers to descend to a very low altitude without southward electric field and this could explain the observed relationships between Es and SSLs in Hefei and Haikou: only the high altitude SSLs (e.g. with a peak altitude above $96 \mathrm{~km}$ ) had an obvious link with $E_{S}$ and the correlation between lower SSLs (e.g. locating below $96 \mathrm{~km}$ ) and $\mathrm{E}_{\mathrm{S}}$ layers was not clear.

\subsection{Comparisons between SSLs at subtropical area and low latitudes: high temperature versus $E_{S}$}

SSLs were very active and seemed to have a never-ending occurrence in low latitude regions (Cox and Plane, 1998). SSLs in Haikou station $\left(19.5^{\circ} \mathrm{N}\right)$ had a greater frequency (with a value of 1 event per 5.3 hours) than in Hefei station $\left(31.8^{\circ} \mathrm{N}\right)$ (with a value of 1 event per 9 hours) (red column in Figure 20). The occurrence frequency of Haikou SSLs even reached 1 event per 2.7 hours ( 0.37 events per hour $)$ in some months (red line in Figure 21(a)). The total 186 SSL events observed by Haikou sodium lidar occurred in 110 single nights, with an average of 1.7 events per night. The total 142 SSLs in Hefei occurred in 99 nights, with an average value of 1.4 events per night.

The low altitude (always within the height of sodium layer) and intense SSLs with large peak densities have been observed frequently in both Hefei and Haikou stations and the simultaneous observations showed a clear link between this type of SSLs and the high temperature induced by the gravity wave breaking.

However, the correlations between SSLs and $\mathrm{E}_{\mathrm{S}}$ are quite different in tropical and subtropical stations. The occurrence frequency of ES layers (pink column in Figure 20), 
SSLs (red column) and the connection between them in low latitude Haikou station and subtropical area were shown in Figure 20(a), respectively. The annual average occurrence frequency of $E_{S}$ in Haikou $(28.5 \%$, the percentage of sample numbers with ES $_{\mathrm{S}}$ signals over total sample numbers, usually 15 minutes per one sample) was three times higher than that in Hefei $(9.2 \%)$. In addition, the proportions of ES layers descending to a very low altitude in both sites were shown in Figure 20(b) and the results suggested that the occurrence frequency of $E_{S}$ locating below $100 \mathrm{~km}$ in Wuhan (with a value of $6.5 \%$ ) was obviously lower than that in Haikou (with a value of $18.2 \%$ ). According to the ES theory, the descending Es would form a SSLs layer when it falls from above to a low altitude below $100 \mathrm{~km}$ (Collins et al., 2002; Cox and Plane, 1998). The low occurrence frequency of ES events, as well as the little proportion of $E_{S}$ descending to $100 \mathrm{~km}$ altitude, probably contributed to the lack of connection between $E_{S}$ and SSLs in the subtropical area.

In addition, although a good one-to-one relationship between SSLs and ES was observed in Haikou, the link between the monthly occurrence frequency of ES and total SSLs occurrence frequency was insignificant (Figure 21(a) and 21(b)). The linear regression between monthly occurrence frequencies of $E_{S}$ and SSLs (Figure 21(b)) did not yield a significant statistical correlation (correlation coefficient $=-0.07$, with $p$ value $=0.82$ ). However, the link between $\mathrm{E}_{\mathrm{S}}$ and SSLs is closer above $96 \mathrm{~km}$ than in other altitudes at Haikou station (Figure 21(c) and 21(d)). The linear regression between monthly occurrence frequency of $\mathrm{E}_{\mathrm{S}}$ and SSLs gives a correlation coefficient of 0.27 for all the months. 
These results further support the above observation: in the subtropical area and low latitude area, SSLs above $96 \mathrm{~km}$ are generally linked with Es layers and SSLs below 96 $\mathrm{km}$ are more likely connected with temperature controlled mechanism.

However, it is important to note that there are still some difficulties in our theory. First, we assumed all SSLs discussed were generated locally. The possibility of SSLs being advected to the site could not be ruled out, according to the current state of understanding. In this case, if an $\mathrm{E}_{\mathrm{S}}$ layer has descended below $96 \mathrm{~km}$ a large distance from the lidar station, most metallic ions will be neutralized due to the short lifetime and then a patch of neutral $\mathrm{Na}$ atoms would be advected to the range of the lidar beam. So the low altitude SSLs might be observed alone, even if the sodium atoms are neutralized from Es. This challenging point is however beyond the aim of this paper that focuses on documenting and summarizing the regional characters of SSLs. A follow-up study on examining whether the sodium atoms for SSLs are created locally or by advection is in progress, using five channels of lidar beams at both Hefei (one channel of USTC sodium lidar and two channels of USTC wind/temperature lidar) and Wuhan (one channel of WIPM lidar and WU lidar, respectively).

Second, the size of the icy dust is assumed to be $10 \mathrm{~nm}$, which may be discovered by extremely sensitive radars (such as radars at Arecibo and Jicamarca). But as far as we know, no radars at low latitudes have ever reported echoes from the height range where SSLs occur. This may be explained by the reason that the cold layer does not last long enough for particles to grow to the point where they cause significant electron biteouts and/or affect local electron transport. 
Third, the actual progression to form a SSL during both cold phase and hot phase might be much more complex than our model suggests. Sodium atoms absorbed by the icy dust reservoir may react with $\mathrm{H}_{2} \mathrm{O}$ to form the $\mathrm{NaOH}$ intermediary (Vondrak et al., 2006), so it can be reasonably assumed that more exotic chemistry might occur during the triggering phase in order to release free sodium atoms through some yet undetermined reduction reactions. More information about the chemical reactions between sodium as well as some other related minor constituents and the ice particles could be seen from the more comprehensive works of John Plane's group (Murray and Plane, 2003; Murray and Plane, 2004; Murray and Plane, 2005; Plane, 2000), which may greatly help the ultimate modification and improvement of our model in the future.

Fourth, the formation of the ice particles, and coating by a substantial amount of $\mathrm{Na} / \mathrm{NaOH}$, has to happen in a period of a few hours at most. Whether there is sufficient time to achieve a high density of $\mathrm{Na} / \mathrm{NaOH}$ on the particles is still uncertain. Therefore, future lab measurements and modelling will be required to provide more support for or even the refutation of the ice particle theory.

\subsection{Possible reasons for the rarity of SSLs near $40^{\circ} \mathrm{N}$}

SSLs rarely occurred in a mid-latitude region near $40^{\circ} \mathrm{N}$ in North America (Batista et al., 1991; Beatty et al., 1988; Beatty et al., 1989; Clemesha et al., 1988; Cox and Plane, 1998; Fan et al., 2007a; Kane et al., 1991; Kirkwood and von Zahn, 1991; Michaille et al., 2001; Rajasekhar and Plane, 1993; Senft et al., 1989; Zhou and Mathews, 1995; Zhou et al., 1993). Although observations in this area started from 
1970s, the first SSL event was reported in late 1980s (Senft et al., 1989). The Urbana, Illinois $\left(40^{\circ} \mathrm{N}, 88^{\circ} \mathrm{W}\right)$ CEDAR lidar operated on March and April, 1988, and observed five occasions resembling SSLs (Beatty et al., 1988). The Urbana, Illinois lidar operated for 350 hours in 53 single nights throughout the whole year of 1988, but only two convincing SSL occasions with periods less than 2 hours in total were observed on the night of Oct 30 (Senft et al., 1989). However, recent observations by sodium lidar at Beijing $\left(40.5^{\circ} \mathrm{N}, 116.0^{\circ} \mathrm{E}\right)$ revealed that although not frequently, SSLs could also have some occurrence at this mid latitude station (Jiao et al., 2015; Jiao et al., 2014; Yuan et al., 2014).

From the existing results, more and more evidences suggested that SSLs in this region (including both North America and central China) were inclined to be neutralized from metal ions in the $\mathrm{E}_{\mathrm{S}}$ (Gardner et al., 1993; Wang et al., 2012; Williams et al., 2007). A simultaneous observation of $\mathrm{E}_{\mathrm{S}}$, $\mathrm{SSLs}, \mathrm{Fe}_{\mathrm{S}}$ and $\mathrm{Ca}^{+} \mathrm{S}$ in Urbana revealed that complex SSLs, $\mathrm{Fe}_{S}$ and $\mathrm{Ca}^{+} \mathrm{S}$ layers at $100 \mathrm{~km}$ occurred accompanied by $\mathrm{E}_{\mathrm{S}}$ (Gardner et al., 1993). Another sodium lidar in Fort Collins, Colorado $\left(40.6^{\circ} \mathrm{N}, 105^{\circ} \mathrm{W}\right)$ observed a large SSL on Jun 2, 2002 (Williams et al., 2007). The peak density of this event was located at $101 \mathrm{~km}$ and $104 \mathrm{~km}$, with a enhancement factor over 500 times and a duration from 03:30 UT to 05:00 UT (Williams et al., 2007). An Es layer with a foEs value of $14.3 \mathrm{MHz}$ was observed by a nearest ionosonde, thirty minutes before the onset of the SSL (at 03:00 UT), and it was the strongest Es observed of the whole year (Williams et al., 2007). However, there was no distinct increase of temperature throughout this SSL event (Williams et al., 2007). On the other hand, profiles of the 
sodium density observed by Beijing lidar on May 22, 2010 was shown in Figure 22(a), exhibited a double sodium layer and SSL (Wang et al., 2012). The double layer appeared above $110 \mathrm{~km}$ before 14:30 UT, and descended to $100 \mathrm{~km}$ as it was dissipating gradually (Wang et al., 2012). At about 16:30 UT, the double peak structure disappeared and the SSL began to form (Wang et al., 2012). This complex event showed a particularly close relationship to Es. The double peak lasted from 14:06 UT to 16:06 UT, meanwhile the foEs values were apparently large with an average of $7.27 \mathrm{MHz}$ (Figure 22(b)). The double peak disappeared after 16:06 UT, and the foEs also dropped steeply from that time (Figure 22(b)). So the double sodium layers were likely generated from sodium ions in the accompanied $E_{S}$ layers.

Based on the Es related forming mechanism, the discrepancy of occurrences for SSLs in North America and central China could be explained by the comparison study between SSLs in Utah State University $\left(41.7^{\circ} \mathrm{N}, 111.8^{\circ} \mathrm{W}\right)$ and Beijing China $\left(40.2^{\circ} \mathrm{N}\right.$, $116.1^{\circ} \mathrm{E}$ ) (Yuan et al., 2014). This study showed that the lower E region above Beijing was dominated by one of the strong peaks of the diurnal wave number 4 pattern, but North America was dominated by migrating tides most of the time, which had relatively small amplitudes (Yuan et al., 2014). The total diurnal amplitude was between $10 \mathrm{~m} / \mathrm{s}$ and $15 \mathrm{~m} / \mathrm{s}$ at $110 \mathrm{~km}$ altitude above Beijing, while the diurnal tidal amplitude above the Logan area in July was fairly small (less than $5 \mathrm{~m} / \mathrm{s}$ ) (Yuan et al., 2014). Furthermore, as Christakis et al. (2009) summarized, the diurnal tide controlled fully the formation and descent of the metallic $E_{S}$ layers at lower altitudes and higher altitude $E_{S}$ layers formed presumably associated with semidiurnal tides (Christakis et al., 2009). So the 
diurnal tides played distinct roles in controlling the lower E region above these two mid-latitude regions, which might be the reason for the difference in the occurrence of Nas in Beijing and that in Logan.

\section{Conclusions}

Observations of the SSLs from the stations all over the world suggested that the SSLs have distinct characteristics, including the occurrence frequency and time, in different latitudes and altitudes. The simultaneous observations of SSLs, Es, water vapor and temperature indicated that both the temperature control mechanism and ES theory play important roles in the formation of the SSLs in different latitudes and altitudes.

In high latitude, most of summer SSLs are located below $97 \mathrm{~km}$ (33/40 events), while the average altitude of winter SSLs are much higher and nearly half of them formed above $97 \mathrm{~km}$ (16/35 events). SSLs in high latitude occur frequently between 20 and 01 LT, with a maximum frequency around the midnight. The simultaneous observations of the SSLs and Es in high latitude suggested that the SSLs and ES layers have a similar occurrence time and are located at almost the same altitude. Thus $E_{S}$ layers may form the high latitude SSLs directly.

In subtropical Hefei station, SSLs have stable frequency from 20 LT to 03 LT and the averaged altitude of summer SSLs is higher than that of winter SSLs. The Es are not essential for most SSLs in the subtropical area. SSLs in this area are closely linked with temperature, in particular for the SSLs below $96 \mathrm{~km}$. A proposed temperature 
controlled icy dust sodium reservoir model, which could explain most observations, is a possible candidate for the formation mechanism of these SSLs.

The SSLs in tropical Haikou station show similar characteristics with the SSLs in subtropical area except the seasonal difference in occurrence frequency of the SSLs above $96 \mathrm{~km}$. Both Es layers and temperature control mechanism likely contribute to the formation of SSLs in tropical area. SSLs below $96 \mathrm{~km}$ have a closer link with the high temperatures, while SSLs above $96 \mathrm{~km}$ are more likely controlled by the $\mathrm{E}_{\mathrm{S}}$ mechanism.

In summary, high latitude SSLs are mostly influenced by ES layers, whose seasonal variations of the occurrence and vertical locations were suggested to be controlled by solar activity and electric field. SSLs in the subtropical area were mainly controlled by the temperature variations, most likely to be caused by the gravity wave activities. The low latitude SSLs in Haikou station were probably controlled by the high temperature theory and $E_{S}$ mechanism together.

\section{Acknowledgement}

We acknowledge the use of data from the Chinese Meridian Project, Sounding of the Atmosphere with Broadband Emission Radiometry (SABER) on the Thermosphere Ionosphere Mesosphere Energetics and Dynamics (TIMED) satellite, and the Microwave Limb Sounder (MLS) on the EOS Aura spacecraft. This work is supported by the Project (KZZD-EW-0101) of Chinese Academy of Sciences, the National Basic Research Program of China grant 2012CB825605, the National Natural Science 
Foundation of China (41504177, 41025016, 41274150 and 41421063). We thank reviewer \#1 for his/her contributions in this thorough review and the great help in preventing us from expressing any inaccurate or plainly wrong statements. We also thank reviewer \#3's more critical comments for helping us improve the quality of our scientific work. The editor's role in facilitating the peer-review of this paper is also greatly appreciated. We wish to thank Willie Soon from Harvard-Smithsonian Center for Astrophysics, Cambridge, MA 02138, USA for his help in many useful discussions and English polishing. The first author Shican would like to extend a professional thank to Professor H.Yan (her husband) for his help in improving this paper.

\section{References}

Batista, P. P., B. R. Clemesha, I. S. Batista and D. M. Simonich, 1989. Characteristics of the sporadic sodium layers observed at $23^{\circ} \mathrm{S}$. Journal of Geophysical Research 94(A11), 15349-15358.

Batista, P. P., B. R. Clemesha and D. M. Simonich, 1991. Horizontal structures in sporadic sodium layers at $23^{\circ} \mathrm{S}$. Geophysical research letters $18(6), 1027-1030$.

Beatty, T. J., R. E. Bills, K. H. Kwon and C. S. Gardner, 1988. CEDAR lidar observations of sporadic Na layers at Urbana, Illinois. Geophysical research letters 15(10), 1137-1140.

Beatty, T. J., R. L. Collins, C. S. Gardner, C. A. Hostetler, C. F. Sechrist and C. A. Tepley, 1989. Simultaneous radar and lidar observations of sporadic $\mathrm{E}$ and $\mathrm{Na}$ layers at Arecibo. Geophysical research letters 16(9), 1019-1022.

Christakis, N., C. Haldoupis, Q. Zhou and C. Meek, 2009. Seasonal variability and descent of midlatitude sporadic E layers at Arecibo. Ann. Geophys 27(3), 923-931.

Clemesha, B. R., 1990. Stratification processes in the atmospheric sodium layer: observations and theory. Advances in Space Research 10(10), 59-70.

Clemesha, B. R., 1995. Sporadic neutral metal layers in the mesosphere and lower thermosphere. Journal of atmospheric and terrestrial physics 57(7), 725-736.

Clemesha, B. R., P. P. Batista and D. M. Simonich, 1988. Concerning the origin of enhanced sodium layers. Geophysical research letters 15(11), 1267-1270.

Clemesha, B. R., V. Kirchhoff, D. M. Simonich and H. Takahashi, 1978. Evidence of an extra-terrestrial source for the mesospheric sodium layer. Geophysical research letters 5(10), 873-876.

Clemesha, B. R., V. Kirchhoff, D. M. Simonich, H. Takahashi and P. P. Batista, 1980. Spaced lidar and nightglow observations of an atmospheric sodium enhancement. Journal of Geophysical 
Research: Space Physics 85(A7), 3480-3484.

Collins, R. L., T. J. Hallinan, R. W. Smith and G. Hernandez, 1996. Lidar observations of a large highaltitude sporadic Na layer during active aurora. Geophysical research letters 23(24), 3655-3658.

Collins, S. C., J. M. C. Plane, M. C. Kelley, T. G. Wright, P. Soldan, T. J. Kane, A. J. Gerrard, B. W. Grime, R. J. Rollason and J. S. Friedman, 2002. A study of the role of ion-molecule chemistry in the formation of sporadic sodium layers. Journal of atmospheric and solar-terrestrial physics 64(7), 845-860.

Cox, R. M. and J. M. C. Plane, 1998. An ion-molecule mechanism for the formation of neutral sporadic Na layers. Journal of Geophysical Research 103(D6), 6349-6359.

Cox, R. M., J. M. C. Plane and J. S. A. Green, 1993. A modelling investigation of sudden sodium layers. Geophysical research letters 20(24), 2841-2844.

Daire, S. E., J. M. C. Plane, S. D. Gamblin, P. Soldan, E. P. Lee and T. G. Wright, 2002. A theoretical study of the ligand-exchange reactions of $\mathrm{Na}+\mathrm{X}$ complexes $\left(\mathrm{X}=\mathrm{O}, \mathrm{O}_{2}, \mathrm{~N}_{2}, \mathrm{CO}_{2}\right.$ and $\left.\mathrm{H}_{2} \mathrm{O}\right)$ : implications for the upper atmosphere. Journal of atmospheric and solar-terrestrial physics 64 , 863-870.

Dou, X. K., S. Qiu, X. H. Xue, T. D. Chen and B. Q. Ning, 2013. Sporadic and Thermospheric Enhanced Sodium Layers Observed by a Lidar Chain over China. Journal of geophysical Research 118(10), 6627-6643.

Dou, X. K., X. H. Xue, T. D. Chen, W. X. Wan, X. W. Cheng, T. Li, C. Chen, S. Qiu and Z. Y. Chen, 2009. A statistical study of sporadic sodium layer observed by sodium lidar at Hefei $\left(31.8^{\circ} \mathrm{N}\right.$, $\left.117.3^{\circ} \mathrm{E}\right)$. Annales Geophysicae 27, 2247-2257.

Dou, X. K., X. H. Xue, T. Li, T. D. Chen, C. Chen and S. Qiu, 2010. Possible relations between meteors, enhanced electron density layers, and sporadic sodium layers. Journal of Geophysical Research: Space Physics 115(A6), A06311, doi:10.1029/2009JA014575.

Fan, Z. Y., J. M. C. Plane and J. Gumbel, 2007a. On the global distribution of sporadic sodium layers. Geophysical research letters 34(15), L15808, doi:10.1029/2007GL030542.

Fan, Z. Y., J. M. C. Plane, J. Gumbel, J. Stegman and E. J. Llewellyn, 2007b. Satellite measurements of the global mesospheric sodium layer. Atmospheric Chemistry and Physics 7(15), 4107-4115.

Friedman, J. S., S. A. Gonzalez, C. A. Tepley, Q. Zhou, M. P. Sulzer, S. C. Collins and B. W. Grime, 2000. Simultaneous atomic and ion layer enhancements observed in the mesopause region over Arecibo during the Coqui II sounding rocket campaign. Geophysical research letters 27(4), 449452.

Fussen, D., F. Vanhellemont, C. Bingen, E. Kyrölä, J. Tamminen, V. Sofieva, S. Hassinen, A. Seppälä, P. Verronen and J.-L. Bertaux, 2004. Global measurement of the mesospheric sodium layer by the star occultation instrument GOMOS. Geophysical research letters 31(24), doi:10.1029/2004GL021618.

Fussen, D., F. Vanhellemont, C. Tétard, N. Mateshvili, E. Dekemper, N. Loodts, C. Bingen, E. Kyrölä, J. Tamminen and V. Sofieva, 2010. A global climatology of the mesospheric sodium layer from GOMOS data during the 2002-2008 period. Atmospheric Chemistry and Physics 10(19), 92259236.

Gardner, C. S., T. J. Kane, D. C. Senft, J. Qian and G. C. Papen, 1993. Simultaneous observations of sporadic E, $\mathrm{Na}, \mathrm{Fe}$, and $\mathrm{Ca}^{+}$layers at Urbana, Illinois: Three case studies. Journal of Geophysical Research: Atmospheres 98(D9), 16865-16873.

Gardner, C. S., X. Tao and G. C. Papen, 1995. Observations of strong wind shears and temperature 
enhancements during several sporadic Na layer events above Haleakala. Geophysical research letters 22(20), 2809-2812.

Gong, S. S., G. T. Yang, J. M. Wang, B. M. Liu, X. W. Cheng, J. Y. Xu and W. X. Wan, 2002. Occurrence and characteristics of sporadic sodium layer observed by lidar at a mid-latitude location. Journal of atmospheric and solar-terrestrial physics 64(18), 1957-1966.

Gu, Y. Y., J. Qian, G. C. Papen, G. R. Swenson and P. J. Espy, 1995. Concurrent observations of auroral activity and a large sporadic sodium layer event during ANLC-93. Geophysical research letters 22(20), 2805-2808.

Hansen, G. and U. von Zahn, 1990. Sudden sodium layers in polar latitudes. Journal of atmospheric and terrestrial physics 52(6), 585-608.

Hecht, J., T. Kane, R. Walterscheid, C. Gardner and C. Teplky, 1993. Simultaneous nightglow and Na lidar observations at Arecibo during the AIDA-89 campaign. Journal of atmospheric and terrestrial physics 55(3), 409-423.

Heinrich, D., H. Nesse, U. Blum, P. Acott, B. Williams and U.-P. Hoppe, 2008. Summer sudden Na number density enhancements measured with the ALOMAR Weber Na Lidar. Annales Geophysicae 26, 1057-1069.

Heinselman, C. J., J. P. Thayer and B. J. Watkins, 1998. A high-latitude observation of sporadic sodium and sporadic E-layer formation. Geophysical research letters 25(16), 3059-3062.

Jiao, J., G. Yang, J. Wang, X. Cheng, F. Li, Y. Yang, W. Gong, Z. Wang, L. Du and C. Yan, 2015. First report of sporadic $\mathrm{K}$ layers and comparison with sporadic $\mathrm{Na}$ layers at Beijing, China $\left(40.6^{\circ} \mathrm{N}\right.$, 116.2 ${ }^{\circ}$ E). Journal of Geophysical Research: Space Physics 120(6), 5214-5225.

Jiao, J., G. Yang, X. Zou, S. Gong, J. Wang, D. Tian, W. Zhang, T. Zhang, X. Yang and J. Fu, 2014. Joint observations of sporadic sodium and sporadic E layers at middle and low latitudes in China. Chinese Science Bulletin 59(29-30), 3868-3876.

Kane, T. J., C. S. Gardner, Q. Zhou, J. D. Mathews and C. A. Tepley, 1993. Lidar, radar and airglow observations of a prominent sporadic Na/sporadic $E$ layer event at Arecibo during AIDA-89. Journal of atmospheric and terrestrial physics 55(3), 499-511.

Kane, T. J., C. A. Hostetler and C. S. Gardner, 1991. Horizontal and vertical structure of the major sporadic sodium layer events observed during ALOHA-90. Geophysical research letters 18(7), $1365-1368$.

Kirkwood, S., 1997. Thin ion layers in the high-latitude lower ionosphere. Advances in Space Research 19(1), 149-158.

Kirkwood, S. and P. N. Collis, 1989. Gravity wave generation of simultaneous auroral sporadic- $E$ layers and sudden neutral sodium layers. Journal of atmospheric and terrestrial physics 51(4), 259-269.

Kirkwood, S. and H. Nilsson, 2000. High-latitude sporadic-E and other thin layers-the role of magnetospheric electric fields. Space Science Reviews 91(3-4), 579-613.

Kirkwood, S. and U. von Zahn, 1991. On the role of auroral electric fields in the formation of low altitude sporadic $E$ and sudden sodium layers. Journal of atmospheric and terrestrial physics 53(5), 389407.

Kirkwood, S. and U. von Zahn, 1993. Formation mechanisms for low-altitude Es and their relationship with neutral Fe Layers: Results from the METAL Campaign. Journal of Geophysical Research: Space Physics 98(A12), 21549-21561.

Kwon, K. H., D. C. Senft and C. S. Gardner, 1988. Lidar observations of sporadic sodium layers at Mauna Kea Observatory, Hawaii. Journal of Geophysical Research: Atmospheres 93(D11), 14199- 
14208

Li, F., A. Z. Liu, G. R. Swenson, J. H. Hecht and W. A. Robinson, 2005. Observations of gravity wave breakdown into ripples associated with dynamical instabilities. Journal of Geophysical Research: Atmospheres (1984-2012) 110(D9), doi:10.1029/2004JD004849.

Liu, Y. and F. Yi, 2009. Behavior of sporadic Na layers on small time scale. Journal of atmospheric and solar-terrestrial physics 71(12), 1374-1382.

$\mathrm{Ma}, \mathrm{Z}$. and F. Yi, 2010. High-altitude sporadic metal atom layers observed with $\mathrm{Na}$ and $\mathrm{Fe}$ lidars at $30^{\circ} \mathrm{N}$. Journal of atmospheric and solar-terrestrial physics 72(5), 482-491.

Macdougall, J. W. and P. T. Jayachandran, 2005. Sporadic E at cusp latitudes. Journal of atmospheric and solar-terrestrial physics 67(15), 1419-1426.

Macdougall, J. W., P. T. Jayachandran and J. M. C. Plane, 2000a. Polar cap Sporadic-E: part 1, observations. Journal of atmospheric and solar-terrestrial physics 62(13), 1155-1167.

Macdougall, J. W., J. M. C. Plane and P. T. Jayachandran, 2000b. Polar cap Sporadic-E: part 2, modeling. Journal of atmospheric and solar-terrestrial physics 62(13), 1169-1176.

Mathews, J. D., Q. Zhou, C. R. Philbrick, Y. T. Morton and C. S. Gardner, 1993. Observations of ion and sodium layer coupled processes during AIDA. Journal of atmospheric and terrestrial physics 55(3), 487-498.

Michaille, L., J. B. Clifford, J. C. Dainty, T. Gregory, J. C. Quartel, F. C. Reavell, R. W. Wilson and N. J. Wooder, 2001. Characterization of the mesospheric sodium layer at La Palma. Monthly Notices of the Royal Astronomical Society 328(4), 993-1000.

Miyagawa, H., T. Nakamura, T. Tsuda, M. Abo, C. Nagasawa, T. D. Kawahara, K. Kobayashi, T. Kitahara and A. Nomura, 1999. Observations of mesospheric sporadic sodium layers with the MU radar and sodium lidars. Earth Planets and Space 51(7/8), 785-798.

Murray, B. J. and J. M. C. Plane, 2003. The uptake of atomic oxygen on ice films: Implications for noctilucent clouds. Physical Chemistry Chemical Physics 5(19), 4129-4138.

Murray, B. J. and J. M. C. Plane, 2004. Modelling the impact of noctilucent cloud formation on atomic oxygen and other minor constituents of the summer mesosphere. Atmospheric Chemistry and Physics Discussions 4(6), 7181-7216.

Murray, B. J. and J. M. C. Plane, 2005. Uptake of Fe, Na and K atoms on low-temperature ice: implications for metal atom scavenging in the vicinity of polar mesospheric clouds. Physical Chemistry Chemical Physics 7(23), 3970-3979.

Nagasawa, C. and M. Abo, 1995. Lidar observations of a lot of sporadic sodium layers in mid-latitude. Geophysical research letters 22(3), 263-266.

Nesse, H., M. T. Rietveld, D. Heinrich, B. P. Williams, U.-P. Hoppe, J. Stadsnes, W. Singer, U. Blum, M. I. Sandanger and E. Trondsen, 2008. A case study of a sporadic sodium layer observed by the ALOMAR Weber Na lidar. Annales Geophysicae 26, 1071-1081.

Østerpart, J. O. K., 2011. Na lidar measurements during the ECOMA/Geminids campaign with focus on Na peak density and temperature, Master Thesis of University of Troms $\emptyset$.

Plane, J. M. C., 2000. The role of sodium bicarbonate in the nucleation of noctilucent clouds. Annales Geophysicae 18, 807-814.

Prasanth, P. V., Y. B. Kumar and D. N. Rao, 2007. Lidar observations of sporadic Na layers over Gadanki $\left(13.5^{\circ} \mathrm{N}, 79.2^{\circ} \mathrm{E}\right)$. Annales Geophysicae $25,1759-1766$.

Qian, J., Y. Gu and C. S. Gardner, 1998. Characteristics of the sporadic Na layers observed during the Airborne Lidar and Observations of Hawaiian Airglow/Airborne Noctilucent Cloud 
(ALOHA/ANLC-93) campaigns. Journal of Geophysical Research: Atmospheres 103(D6), 6333-6347.

Qiu, S., Y. Tang and X.K. Dou, 2015. Temperature controlled icy dust reservoir of sodium: A possible mechanism for the formation of sporadic sodium layers. Advances in Space Research 55(11), 2543-2565.

Rajasekhar, B. and J. M. C. Plane, 1993. An ab initio study of dissociative electron attachment to $\mathrm{NaHCO}_{3}$ and $\mathrm{NaCO}_{3}$, and the role of these reactions in the formation of sudden sodium layers. Geophysical research letters 20(1), 21-24.

Senft, D. C., R. L. Collins and C. S. Gardner, 1989. Mid-latitude lidar observations of large sporadic sodium layers. Geophysical research letters 16(7), 715-718.

Shibata, Y., C. Nagasawa, M. Abo, T. Maruyama, S. Saito and T. Nakamura, 2006. Lidar observations of sporadic $\mathrm{Fe}$ and $\mathrm{Na}$ layers in the mesopause region over equator. Journal of the Meteorological Society of Japan 84(0), 317-325.

Sridharan, S., A. K. Patra, N. Venkateswara Rao and G. Ramkumar, 2009. First simultaneous lidar observations of sodium layers and VHF radar observations of E-region field-aligned irregularities at the low-latitude station Gadanki. Annales Geophysicae 27, 3411-3419.

Vondrak, T., J.M.C. Plane, and S.R. Meech, 2006. Photoemission from sodium on ice: A mechanism for positive and negative charge coexistence in the mesosphere. The Journal of Physical Chemistry B 110(9), 3860-3863.

von Zahn, U. and T. L. Hansen, 1988. Sudden neutral sodium layers: a strong link to sporadic E layers. Journal of atmospheric and terrestrial physics 50(2), 93-104.

von Zahn, U., P. von Der Gathen and G. Hansen, 1987. Forced release of sodium from upper atmospheric dust particles. Geophysical research letters 14(1), 76-79.

Wang,C, 2010. New chains of space weather monitoring stations in China. Space Weather 8(8).

Wang, J., Y. Yang, X. Cheng, G. Yang, S. Song and S. Gong, 2012. Double sodium layers observation over Beijing, China. Geophysical research letters 39(15), L15801, doi:10.1029/2012GL052134.

Williams, B. P., F. T. Berkey, J. Sherman and C. Y. She, 2007. Coincident extremely large sporadic sodium and sporadic E layers observed in the lower thermosphere over Colorado and Utah. Annales Geophysicae 25, 3-8.

Williams, B. P., C. L. Croskey, C. Y. She, J. D. Mitchell and R. A. Goldberg, 2006. Sporadic sodium and E layers observed during the summer 2002 MaCWAVE/MIDAS rocket campaign. Annales Geophysicae 24, 1257-1266.

Yi, F., S. Zhang, C. Yu, Y. Zhang, Y. He, F. Liu, K. Huang, C. Huang and Y. Tan, 2013. Simultaneous and common-volume three-lidar observations of sporadic metal layers in the mesopause region. Journal of atmospheric and solar-terrestrial physics 102, 172-184.

Yi, F., S. Zhang, H. Zeng, Y. He, X. Yue, J. Liu, H. Lv and D. Xiong, 2002. Lidar observations of sporadic $\mathrm{Na}$ layers over Wuhan $\left(30.5^{\circ} \mathrm{N}, 114.4^{\circ} \mathrm{E}\right)$. Geophysical research letters 29(9), 1345, 10.1029/2001GL014353.

Yuan, T., J. Wang, X. Cai, J. Sojka, D. Rice, J. Oberheide and N. Criddle, 2014. Investigation of the seasonal and local time variations of the high-altitude sporadic $\mathrm{Na}$ layer ( $\mathrm{Na}_{\mathrm{S}}$ ) formation and the associated midlatitude descending $E$ layer $\left(E_{S}\right)$ in lower E region. Journal of Geophysical Research: Space Physics 119(7), 5985-5999.

Zhou, Q. and J. D. Mathews, 1995. Generation of sporadic sodium layers via turbulent heating of the atmosphere? Journal of atmospheric and terrestrial physics 57(11), 1309-1319. 
Zhou, Q., J. D. Mathews and C. A. Tepley, 1993. A proposed temperature dependent mechanism for the formation of sporadic sodium layers. Journal of atmospheric and terrestrial physics 55(3), 513521. 
Table 1 Observations of the sodium layer all over the world

\begin{tabular}{|c|c|c|c|}
\hline Location & $\begin{array}{l}\text { Geographic } \\
\text { coordinates }\end{array}$ & $\begin{array}{c}\text { Characteristics of sporadic } \\
\text { sodium layers }\end{array}$ & References \\
\hline Heiss Island & $80.5^{\circ} \mathrm{N}, 57.5^{\circ} \mathrm{E}$ & & 1 \\
\hline Svalbard & $78.0^{\circ} \mathrm{N}, 15.5^{\circ} \mathrm{E}$ & & 2 \\
\hline Tromso, Norway & $69.6^{\circ} \mathrm{N}, 19.2^{\circ} \mathrm{E}$ & $\begin{array}{c}\text { Sodium density decreased during } \\
\text { auroral activity }\end{array}$ & 3 \\
\hline Andoya & $69.1^{\circ} \mathrm{N}, 15.8^{\circ} \mathrm{E}$ & Frequent & 4 \\
\hline Andenes, Norway & $69.3^{\circ} \mathrm{N}, 16.1^{\circ} \mathrm{E}$ & Frequent & 5 \\
\hline ALOMAR & $69.3^{\circ} \mathrm{N}, 16.0^{\circ} \mathrm{E}$ & Frequent & 6 \\
\hline $\begin{array}{c}\text { Sondrestrom, } \\
\text { Kangerlussuaq, } \\
\text { Greenland }\end{array}$ & $66.9^{\circ} \mathrm{N}, 50.9^{\circ} \mathrm{W}$ & $\begin{array}{l}\text { Frequent, associated with electron } \\
\text { layers }\end{array}$ & 7 \\
\hline Poker Flat & $65.1^{\circ} \mathrm{N}, 147.5^{\circ} \mathrm{W}$ & & 8 \\
\hline $\begin{array}{c}\text { Kuhlungsborn, } \\
\text { Germany }\end{array}$ & $54.1^{\circ} \mathrm{N}, 11.8^{\circ} \mathrm{E}$ & & 9 \\
\hline Saskatoon & $52.1^{\circ} \mathrm{N}, 106.6^{\circ} \mathrm{W}$ & & 10 \\
\hline Winkfield & $51.4^{\circ} \mathrm{N}, 0.7^{\circ} \mathrm{W}$ & Seldom & 11 \\
\hline Haute Provence & $44.6^{\circ} \mathrm{N}, 5.9^{\circ} \mathrm{E}$ & Seldom & 12 \\
\hline Colorado & $40.7^{\circ} \mathrm{N}, 104.9^{\circ} \mathrm{W}$ & Seldom & 13 \\
\hline Beijing & $40.2^{\circ} \mathrm{N}, 116.2^{\circ} \mathrm{E}$ & Seldom & 14 \\
\hline Illinois & $40.1^{\circ} \mathrm{N}, 88.2^{\circ} \mathrm{W}$ & Seldom & 15 \\
\hline $\begin{array}{c}\text { Wallops Island, } \\
\text { Virginia }\end{array}$ & $37.5^{\circ} \mathrm{N}, \quad 75.5^{\circ} \mathrm{W}$ & & 16 \\
\hline Menlo Park & $37.4^{\circ} \mathrm{N}, 122.1^{\circ} \mathrm{W}$ & & 17 \\
\hline New Mexico & $34.7^{\circ} \mathrm{N}, 106.5^{\circ} \mathrm{W}$ & & 18 \\
\hline Tokyo & $35.4^{\circ} \mathrm{N}, 139.4^{\circ} \mathrm{E}$ & Frequent & 19 \\
\hline Tucson & $32.2^{\circ} \mathrm{N}, 110.9^{\circ} \mathrm{W}$ & & 20 \\
\hline Hefei & $31.8^{\circ} \mathrm{N}, 117.2^{\circ} \mathrm{E}$ & Frequent & 21 \\
\hline Wuhan & $30.5^{\circ} \mathrm{N}, 114.3^{\circ} \mathrm{E}$ & Frequent & 22 \\
\hline La Palma & $28.7^{\circ} \mathrm{N}, \quad 17.9^{\circ} \mathrm{W}$ & Frequent & 23 \\
\hline Lijiang & $26.8^{\circ} \mathrm{N}, 100.1^{\circ} \mathrm{E}$ & & 24 \\
\hline Hawaii Haleakala & $20.7^{\circ} \mathrm{N}, 156.2^{\circ} \mathrm{W}$ & $\begin{array}{l}\text { Very frequent, associated with high } \\
\text { temperature }\end{array}$ & 25 \\
\hline Hawaii Mauna & $19.5^{\circ} \mathrm{N}, 155.6^{\circ} \mathrm{W}$ & $\begin{array}{l}\text { Very frequent, associated with high } \\
\text { temperature }\end{array}$ & 26 \\
\hline Haikou & $19.5^{\circ}, 109.1^{\circ} \mathrm{E}$ & very frequent & 27 \\
\hline Arecibo & $18.3^{\circ} \mathrm{N}, 66.8^{\circ} \mathrm{W}$ & $\begin{array}{l}\text { Very frequent, associated with high } \\
\text { temperature and electron layer }\end{array}$ & 28 \\
\hline
\end{tabular}




\begin{tabular}{|c|c|c|c|}
\hline Gadanki & $13.5^{\circ} \mathrm{N}, 79.2^{\circ} \mathrm{E}$ & Frequent & 29 \\
\hline $\begin{array}{c}\text { Kototabang, } \\
\text { Indonesia }\end{array}$ & $0.2^{\circ} \mathrm{S}, 100.3^{\circ} \mathrm{E}$ & Occasional & 30 \\
\hline Alcantara & $2.3^{\circ} \mathrm{S}, 44.5^{\circ} \mathrm{W}$ & Occasional & 31 \\
\hline $\begin{array}{c}\text { Sao Jose do } \\
\text { Campos }\end{array}$ & $23.2^{\circ} \mathrm{S}, 45.9^{\circ} \mathrm{W}$ & Frequent & 32 \\
\hline $\begin{array}{c}\text { Christchurch, New } \\
\text { Zealand }\end{array}$ & $43.6^{\circ} \mathrm{S}, 172.6^{\circ} \mathrm{E}$ & & 33 \\
\hline $\begin{array}{c}\text { Rothera Research } \\
\text { Station }\end{array}$ & $67.3^{\circ} \mathrm{S}, 68.1^{\circ} \mathrm{W}$ & $\mathrm{Fe}_{S}$, frequent & 34 \\
\hline Syowa & $69.0^{\circ} \mathrm{S}, 39.6^{\circ} \mathrm{E}$ & & 35 \\
\hline South Pole & $90^{\circ} \mathrm{S}$ & & 36 \\
\hline \multicolumn{4}{|c|}{ Airborne Observations } \\
\hline $\begin{array}{l}\text { OSIRIS on the } \\
\text { Odin satellite }\end{array}$ & $\begin{array}{l}\text { global distribution } \\
\text { at } 0600 \text { and } 1800 \\
\text { hrs local time }\end{array}$ & $\begin{array}{l}\text { More prevalent in the southern } \\
\text { hemisphere, with a particularly } \\
\text { active region extending from South } \\
\text { America at latitudes greater than } \\
40^{\circ} \mathrm{S} \text { to the Antarctic peninsula. }\end{array}$ & 37 \\
\hline $\begin{array}{l}\text { GOMOS on the } \\
\text { ENVISAT satellite }\end{array}$ & $\begin{array}{c}\text { global } \\
\text { measurement of } \\
\text { the sodium layer }\end{array}$ & & 38 \\
\hline $\begin{array}{c}\text { ALOHA/ANLC-93 } \\
\text { campaign }\end{array}$ & $\begin{array}{c}16.6^{\circ} \mathrm{N}-55.5^{\circ} \mathrm{N} \\
91.6^{\circ} \mathrm{W}-164.9^{\circ} \mathrm{W}\end{array}$ & $\begin{array}{l}\text { frequent, associated with high } \\
\text { temperature or/and auroral } \\
\text { electron precipitation }\end{array}$ & 39 \\
\hline
\end{tabular}

1. (Juramy et al., 1981; Megie et al., 1978b); 2. (Gardner et al., 1988; Henriksen et al., 1980); 3.

(Tsuda et al., 2013); 4. (Tilgner and Zahn, 1988; Williams et al., 2006); 5. (Hansen and Von Zahn, 1990; Heinrich et al., 2008; Von Zahn et al., 1989); 6. (Heinrich et al., 2008; Nesse et al., 2008); 7. (Heinselman et al., 1998; Heinselman, 2000); 8. (Collins et al., 1996); 9.(Hoffner and Friedman, 2004; Hoffner and Friedman, 2005); 10. (Bullock and Hunten, 1961; Hunten et al., 1964); 11. (Gibson and Sandford, 1971; Sandford and Gibson, 1970); 12. (Granier et al., 1989; Granier and Megie, 1982; Megie and Blamont, 1977; Megie et al., 1978a); 13. (Huang et al., 2013; Plane et al., 1999; Williams et al., 2007); 14. (Dou et al., 2013; Wang et al., 2012); 15. (Beatty et al., 1988; Gardner and Voelz, 1987; Gardner et al., 1986; Gardner et al., 1993; Kane and Gardner, 1993; 
Plane et al., 1999; Senft et al., 1989); 16. (Donahue and Meier, 1967); 17. (Hake et al., 1972); 18. (Xiong et al., 2003); 19. (Miyagawa et al., 1999; Nagasawa and Abo, 1995); 20. (Ge et al., 1997); 21. (Dou et al., 2009; Dou et al., 2013; Dou et al., 2010); 22.(Chen and Yi, 2011; Cheng et al., 2007; Gong et al., 2003; Gong et al., 2002; Gong et al., 1997; Liu and Yi, 2009; Ma and Yi, 2010; Yang et al., 2002; Yi et al., 2009; Yi et al., 2007; Yi et al., 2013; Yi et al., 2002); 23. (Michaille et al., 2001); 24. (Xue et al., 2013); 25. (Gardner et al., 1991; Gardner et al., 1995; Qian et al., 1998); 26. (Kane et al., 1991; Kwon et al., 1988; Zhao et al., 2005); 27.(Dou et al., 2013); 28. (Beatty et al., 1989; Delgado et al., 2012; Friedman et al., 2000; Hecht et al., 1993; Kane et al., 1993; Kane et al., 2001; Mathews et al., 1993a; Mathews et al., 1993b; Sarkhel et al., 2012; Zhou et al., 1993; Zhou and Mathews, 1995); 29. (Lokanadham et al., 2010; Prasanth et al., 2006; Sridharan et al., 2009); 30. (Shibata et al., 2006); 31. (Clemesha et al., 1998); 32. (Batista et al., 1989; Batista et al., 1991; Batista et al., 2002; Clemesha, 1995; Clemesha et al., 1997; Clemesha et al., 1980; Clemesha et al., 1992; Clemesha et al., 2004; Kirchhoff and Clemesha, 1973; Kirchhoff and Clemesha, 1983; Simonich and Clemesha, 2008; Simonich et al., 2005); 33.(Hunten et al., 1964); 34.(Diettrich et al., 2006); 35.(Nomura et al., 1987); 36.(Gardner et al., 2005; Plane et al., 1998); 37.(Fan et al., 2007a; Fan et al., 2007b); 38.(Fussen et al., 2004; Fussen et al., 2010); 39.(Gu et al., 1995; Qian et al., 1998) 
Table 2a Parameters of the summertime SSLs observed by ALOMAR wind / temperature lidar from 2001 to 2006 (Heinrich et al., 2008)

\begin{tabular}{|c|c|c|c|}
\hline Date & $\begin{array}{c}\text { Beginning } \\
\text { Time (LT) }\end{array}$ & $\begin{array}{c}\text { Starting } \\
\text { Height } \\
(\mathrm{km})\end{array}$ & Factor \\
\hline $20060601 /$ & $22: 48$ & 93.9 & 10 \\
\hline $20050718 /$ & $22: 41$ & 93 & 10 \\
\hline $20050720 /$ & $22: 04$ & 92 & 2 \\
\hline $20020625 /$ & $16: 58$ & 95 & 6 \\
\hline $20020625 /$ & $23: 45$ & 92.6 & 2 \\
\hline $20020701 /$ & $22: 00$ & 94.5 & 5 \\
\hline $20020701 /$ & $22: 07$ & 92.5 & 6 \\
\hline $20020702 /$ & $22: 50$ & 93 & 8 \\
\hline $20020704 /$ & $2: 00$ & 94.5 & 5 \\
\hline $20010711 /$ & $22: 17$ & 95 & 5 \\
\hline $20010711 /$ & $23: 45$ & 92 & 10 \\
\hline $20010619 /$ & $00: 50$ & 93.2 & 2 \\
\hline $20010620 /$ & $00: 25$ & 94.5 & 10 \\
\hline $20010620 /$ & $00: 33$ & 93.6 & 4 \\
\hline $20010706 /$ & $1: 17$ & 94 & 6 \\
\hline $20010706 /$ & $1: 25$ & 97 & 10 \\
\hline Average & & 93.8 & 6 \\
\hline
\end{tabular}


Table 2b Parameters of the un-summertime SSLs observed by ALOMAR wind / temperature lidar from 2001 to 2006 (Heinrich et al., 2008)

\begin{tabular}{|c|c|c|c|}
\hline Date & $\begin{array}{c}\text { Beginning } \\
\text { Time (LT) }\end{array}$ & $\begin{array}{c}\text { Starting } \\
\text { Height } \\
(\mathrm{km})\end{array}$ & Factor \\
\hline $20060218 /$ & $00: 27$ & 101 & 2 \\
\hline $20060204 /$ & $21: 34$ & 102 & 3 \\
\hline $20051119 /$ & $21: 07$ & 101 & 4 \\
\hline $20051105 /$ & $22: 31$ & 105 & 3 \\
\hline $20051105 /$ & $23: 14$ & 92 & 3 \\
\hline $20050207 /$ & $19: 39$ & 103 & 4 \\
\hline $20050207 /$ & $19: 47$ & 110 & 4 \\
\hline $20030128 /$ & $20: 26$ & 104 & 3 \\
\hline $20020114 /$ & $22: 10$ & 98 & 3 \\
\hline $20010327 /$ & $20: 41$ & 105 & 4 \\
\hline $20010323 /$ & $20: 15$ & 103 & 5 \\
\hline $20010323 /$ & $21: 25$ & 108 & 2 \\
\hline $20010322 /$ & $20: 16$ & 104 & 5 \\
\hline $20010317 /$ & $20: 23$ & 103 & 4 \\
\hline $20010317 /$ & $22: 28$ & 101 & 3 \\
\hline Average & & 102.7 & 3 \\
\hline
\end{tabular}


Table 3 The vertical height difference between SSLs location and temperature minimum $\left(\Delta z=z(S S L)-z\left(T_{\min }\right)\right)$ (Hansen and Von Zahn, 1990)

\begin{tabular}{|c|c|c|c|}
\hline$\Delta z \quad(\mathrm{~km})$ & All SSLs event & Jul-Aug & Oct-Mar \\
\hline$>+4.5$ & 4 & -- & 4 \\
\hline$+4 \pm 0.5$ & -- & -- & -- \\
\hline$+3 \pm 0.5$ & 1 & -- & 1 \\
\hline$+2 \pm 0.5$ & 6 & 2 & 4 \\
\hline$+1 \pm 0.5$ & 1 & -- & 1 \\
\hline $0 \pm 0.5$ & 6 & 3 & 3 \\
\hline$-1 \pm 0.5$ & 3 & 1 & 2 \\
\hline$-2 \pm 0.5$ & 2 & -- & 2 \\
\hline$-3 \pm 0.5$ & 8 & 4 & 4 \\
\hline$-4 \pm 0.5$ & -- & -- & -- \\
\hline$<-4.5$ & 1 & -- & 1 \\
\hline
\end{tabular}


Table 4 Simultaneous observations of the SSLs and $\mathrm{E}_{\mathrm{S}}$ at Andenes, Norway, from 1986 to 1987 (Von Zahn and Hansen, 1988)

\begin{tabular}{|c|c|c|c|c|}
\hline Date & $\begin{array}{c}\text { Onset of } \\
\text { SSLs (UT) }\end{array}$ & $\begin{array}{c}\text { Start altitude } \\
\text { of SSLs (km) }\end{array}$ & $\begin{array}{c}\text { Occurrence } \\
\text { of } \mathrm{E}_{\mathrm{S}}(\mathrm{UT})\end{array}$ & $\begin{array}{c}\text { Altitude of } \\
\mathrm{E}_{\mathrm{S}}(\mathrm{km})\end{array}$ \\
\hline $19860119 /$ & 2331 & 95.5 & 0000 & 98 \\
\hline $19860120 /$ & 2228 & 97 & 2220 & 101 \\
\hline $19860812 /$ & 2343 & 96.2 & 2240 & 100 \\
\hline & & & 2300 & 100 \\
\hline & & & 2320 & 94 \\
\hline & & & 2340 & 94 \\
\hline $19860815 /$ & 2203 & 97.8 & 2140 & 100 \\
\hline & 2213 & 94.3 & 2200 & 94 \\
\hline & & & 2220 & 94 \\
\hline $19860820 /$ & 2110 & 94.8 & 2120 & 94 \\
\hline 19860823 & 2059 & 95 & 2100 & 100 \\
\hline 19870302 & 2115 & 98 & 2120 & 100 \\
\hline & 2149 & 95 & 2130 & 100 \\
\hline & 2214 & 96 & 2210 & 97 \\
\hline
\end{tabular}


Table 5 The relationship between all the 142 SSLs occasions and simultaneous $E_{S}$ as well as high temperatures

\begin{tabular}{|c|c|c|c|c|c|c|c|}
\hline SSL event & $\begin{array}{l}\text { Peak } \\
\text { height } \\
\text { of SSL } \\
(\mathrm{km})\end{array}$ & $\begin{array}{c}\text { Link with } \\
E_{S}\end{array}$ & $\begin{array}{l}\text { Link with } \\
\text { high } \\
\text { temperature }\end{array}$ & SSL event & $\begin{array}{c}\text { Peak } \\
\text { height of } \\
\text { SSL } \\
(\mathrm{km})\end{array}$ & $\begin{array}{c}\text { Link with } \\
\mathrm{E}_{\mathrm{S}}\end{array}$ & $\begin{array}{l}\text { Link with } \\
\text { high } \\
\text { temperature }\end{array}$ \\
\hline \multirow[t]{2}{*}{ 20110115/ } & 93.2 & bad & -- & -- & 94.8 & good & -- \\
\hline & 92.1 & bad & good & 20120727/ & 98 & bad & -- \\
\hline 20110116/ & 92 & bad & good & -- & 99.2 & bad & -- \\
\hline 20110219/ & 91.8 & bad & good & 20120728/ & 96.5 & good & bad \\
\hline 20110220/ & 93.5 & bad & good & -- & 94.2 & bad & bad \\
\hline \multirow[t]{2}{*}{ 20110221/ } & 91.1 & -- & good & $20120731 /$ & 97.2 & bad & good \\
\hline & 98 & -- & bad & 20120801/ & 93.2 & bad & good \\
\hline 20110223/ & 91.1 & -- & good & -- & 93.5 & bad & good \\
\hline 20110316/ & 92.6 & -- & good & 20120804/ & 92.6 & bad & good \\
\hline \multirow[t]{2}{*}{ 20110324/ } & 98.1 & bad & -- & 20120805/ & 92 & bad & good \\
\hline & 91.2 & bad & -- & -- & 92.6 & bad & good \\
\hline 20110329/ & 93.8 & bad & good & -- & 93.3 & good & good \\
\hline 20110330/ & 93.2 & -- & good & -- & 100.4 & good & bad \\
\hline 20110404/ & 91.1 & -- & good & 20120905/ & 98.6 & bad & good \\
\hline 20110423/ & 89.3 & -- & good & -- & 95.4 & bad & -- \\
\hline 20110424/ & 93 & -- & -- & -- & 90.6 & bad & -- \\
\hline 20110425/ & 91.7 & bad & good & 20120919/ & 98.3 & bad & good \\
\hline 20110427/ & 96.3 & -- & good & 20120924/ & 93.9 & bad & good \\
\hline \multirow[t]{2}{*}{ 20110503/ } & 97.2 & good & good & 20120928/ & 98.1 & bad & good \\
\hline & 91.1 & -- & good & 20120929/ & 93 & bad & good \\
\hline 20110506/ & 96 & bad & -- & 20120930/ & 87.9 & bad & good \\
\hline 20110507/ & 93.9 & -- & -- & 20121105/ & 93.6 & bad & -- \\
\hline \multirow[t]{2}{*}{ 20110518/ } & 95.4 & -- & good & 20130304/ & 94.7 & bad & bad \\
\hline & 100.7 & -- & -- & -- & 94.1 & bad & bad \\
\hline \multirow[t]{3}{*}{ 20110519/ } & 92.1 & -- & good & 20130305/ & 94.2 & bad & good \\
\hline & 102.6 & -- & good & -- & 94.2 & bad & good \\
\hline & 99.8 & -- & good & -- & 93.3 & bad & -- \\
\hline \multirow[t]{2}{*}{ 20110526/ } & 89.7 & -- & -- & -- & 91.2 & bad & -- \\
\hline & 95.9 & -- & -- & 20130307/ & 95.1 & bad & good \\
\hline 20110626/ & 96.8 & -- & -- & 20130308/ & 92.9 & bad & good \\
\hline 20110831/ & 95.7 & -- & good & 20130406/ & 91.7 & bad & good \\
\hline \multirow[t]{2}{*}{ 20110901/ } & 92.4 & -- & -- & $20130411 /$ & 92.3 & bad & good \\
\hline & 92.4 & -- & -- & $20130412 /$ & 92.7 & bad & good \\
\hline
\end{tabular}




\begin{tabular}{|c|c|c|c|c|c|c|c|}
\hline 20111009/ & 94.5 & good & good & 20130426/ & 98.9 & bad & -- \\
\hline 20111017/ & 100.5 & good & -- & 20130427/ & 99 & bad & -- \\
\hline \multirow[t]{2}{*}{ 20111018/ } & 90.6 & bad & -- & -- & 93.9 & bad & -- \\
\hline & 90.9 & bad & good & 20130430/ & 93.9 & bad & good \\
\hline \multirow[t]{3}{*}{$20111026 /$} & 98.6 & bad & -- & -- & 99.5 & good & -- \\
\hline & $?$ & good & -- & $20130512 /$ & 93.2 & good & -- \\
\hline & $?$ & bad & good & 20130513/ & 96 & bad & -- \\
\hline 20111116/ & 93.3 & bad & -- & $20130522 /$ & 93.3 & bad & -- \\
\hline 20111124/ & 91.4 & -- & good & $20130602 /$ & 97.8 & bad & -- \\
\hline 20111125/ & 92.7 & bad & good & 20130603/ & 98 & good & bad \\
\hline 20111126/ & 90.2 & bad & good & -- & 97.7 & good & bad \\
\hline 20111202/ & 94.8 & good & good & 20130604/ & 97.4 & good & bad \\
\hline 20111208/ & 92.6 & bad & good & -- & 93.2 & good & -- \\
\hline 20111209/ & 93.5 & bad & good & 20130613/ & 97.5 & bad & -- \\
\hline 20111212/ & 91.8 & bad & good & -- & 95 & bad & good \\
\hline 20111213/ & 90.9 & bad & good & 20130724/ & 98.7 & bad & good \\
\hline 20111224/ & 90.5 & bad & good & 20130729/ & 94.7 & bad & good \\
\hline \multirow[t]{5}{*}{ 20120217/ } & 95.7 & bad & good & -- & 94.5 & bad & good \\
\hline & 98 & bad & -- & 20130806/ & 92.1 & good & good \\
\hline & 93.6 & bad & -- & $20130812 /$ & 95 & bad & good \\
\hline & 94.7 & bad & good & 20130813/ & 99 & good & bad \\
\hline & 90.6 & bad & good & -- & 95.1 & bad & bad \\
\hline $20120422 /$ & 91.4 & bad & good & 20130814/ & 95.3 & bad & bad \\
\hline 20120427/ & 94.5 & bad & -- & 20130817/ & 94.2 & good & bad \\
\hline \multirow[t]{3}{*}{$20120502 /$} & 97.5 & bad & good & -- & 95.6 & bad & good \\
\hline & 95.7 & bad & good & 20130920/ & 89.7 & bad & good \\
\hline & 93.2 & bad & -- & 20131009/ & 94.5 & -- & bad \\
\hline 20120504/ & 92.1 & bad & good & 20131010/ & -- & -- & good \\
\hline 20120510/ & 96.8 & bad & -- & 20131011/ & 92.1 & bad & -- \\
\hline \multirow[t]{2}{*}{ 20120526/ } & 95 & bad & good & $20131012 /$ & 93 & bad & -- \\
\hline & 96.2 & bad & good & 20131119/ & 96.3 & bad & -- \\
\hline $20120621 /$ & 95.7 & bad & -- & -- & 90 & bad & good \\
\hline 20120720/ & 93.3 & good & good & 20131120/ & 94.2 & bad & good \\
\hline $20120722 /$ & 97.7 & good & -- & -- & 89.4 & bad & good \\
\hline \multirow[t]{2}{*}{ 20120724/ } & 95.7 & good & good & 20131121/ & 96.3 & bad & good \\
\hline & 100 & good & bad & 20131124/ & 91.7 & bad & good \\
\hline \multirow[t]{2}{*}{ 20120726/ } & 95.3 & good & -- & 20131130/ & 92.1 & bad & good \\
\hline & 96.9 & bad & good & $20131202 /$ & 90.9 & bad & good \\
\hline
\end{tabular}


Table 6 The relationship between the 186 SSL occasions and $E_{S}$ layers and high temperatures in Haikou station

\begin{tabular}{|c|c|c|c|c|c|c|c|}
\hline Event & $\begin{array}{c}\text { Peak } \\
\text { height } \\
(\mathrm{km})\end{array}$ & $\begin{array}{c}\text { Correlation } \\
\text { with } E_{S}\end{array}$ & $\begin{array}{l}\text { Correlation } \\
\text { with high } \\
\text { temperature }\end{array}$ & Event & $\begin{array}{l}\text { Peak } \\
\text { height } \\
(\mathrm{km})\end{array}$ & $\begin{array}{c}\text { Correlation } \\
\text { with } E_{S}\end{array}$ & $\begin{array}{l}\text { Correlation } \\
\text { with high } \\
\text { temperature }\end{array}$ \\
\hline 20110205/ & 96.4 & -- & -- & 20120415/ & 94.8 & -- & bad \\
\hline 20110416/ & 90.2 & bad & good & 20120423/ & 97.6 & bad & bad \\
\hline-- & 92.7 & bad & good & 20120430/ & 92.5 & bad & good \\
\hline 20110529/ & 97 & good & good & 20120510/ & 95.5 & -- & good \\
\hline-- & 99.8 & good & good & 20120511/ & 96.4 & -- & good \\
\hline-- & 97 & good & -- & -- & 92.3 & -- & -- \\
\hline-- & 93.5 & good & -- & 20120605/ & 95 & good & -- \\
\hline 20110531/ & 94.3 & good & good & -- & 101.2 & good & -- \\
\hline-- & 91.1 & good & good & 20120701/ & 96.5 & good & good \\
\hline 20110601/ & 95.6 & good & good & $20120702 /$ & 94.8 & good & good \\
\hline 20110606/ & 96.4 & good & good & -- & 93.2 & good & -- \\
\hline-- & 98.2 & good & bad & -- & 94.9 & good & -- \\
\hline 20110611/ & 95.3 & good & good & -- & 97.3 & good & -- \\
\hline-- & 94.9 & good & -- & 20120709/ & 93.7 & bad & -- \\
\hline $20110612 /$ & 92.5 & good & bad & -- & 91.8 & bad & good \\
\hline-- & 101.7 & good & bad & 20120710/ & 94.2 & good & -- \\
\hline 20110614/ & 95.9 & good & -- & -- & 93.7 & good & -- \\
\hline 20110615/ & 91 & good & good & -- & 92.5 & good & good \\
\hline 20110617/ & 93.4 & good & bad & 20120711/ & 94.6 & -- & good \\
\hline 20110630/ & 93.4 & good & good & $20120712 /$ & 101.5 & good & -- \\
\hline 20110701/ & 98.7 & good & good & -- & 94.8 & good & -- \\
\hline 20110704/ & 97.8 & good & bad & -- & 93.1 & bad & -- \\
\hline 20110706/ & 93.7 & good & good & -- & 98 & good & bad \\
\hline 20110724/ & 96.7 & good & -- & 20120730/ & 97.3 & good & -- \\
\hline $20110802 /$ & 96.4 & -- & -- & 20120912/ & 92.7 & good & bad \\
\hline-- & 93.6 & -- & -- & 20120916/ & 94.8 & -- & -- \\
\hline 20110807/ & 95.4 & bad & -- & -- & 92.8 & -- & good \\
\hline 20110809/ & 90.9 & bad & -- & -- & 96.9 & -- & -- \\
\hline 20110810/ & 90.9 & bad & bad & $20120919 /$ & 98.6 & -- & bad \\
\hline $20110811 /$ & 99.2 & good & bad & -- & 90.1 & -- & good \\
\hline-- & 96.8 & good & -- & -- & 93 & -- & -- \\
\hline 20110812/ & 93.8 & bad & good & 20120920/ & 93.5 & -- & -- \\
\hline 20110813/ & 95.7 & good & good & 20121109/ & 89.2 & bad & good \\
\hline
\end{tabular}




\begin{tabular}{|c|c|c|c|c|c|c|c|}
\hline-- & 92.1 & bad & -- & 20121113/ & 96.9 & bad & bad \\
\hline 20110814/ & 91.6 & good & good & -- & 97.3 & bad & good \\
\hline 20110816/ & 96.3 & good & good & -- & 94.9 & bad & bag \\
\hline-- & 96.1 & good & $?$ & -- & 92.4 & good & -- \\
\hline 20110819/ & 88.1 & good & good & $20121220 /$ & 98.8 & bad & -- \\
\hline 20110820/ & 92.2 & good & bad & 20121221/ & 101.4 & bad & -- \\
\hline 20110822/ & 98.9 & -- & bad & 20130113/ & 93.7 & bad & bad \\
\hline-- & 92 & bad & good & 20130130/ & 98.1 & good & bad \\
\hline 20110829/ & 92.5 & -- & good & -- & 97.7 & bad & -- \\
\hline 20110831/ & 99.1 & good & -- & -- & 95.7 & good & -- \\
\hline-- & 90.6 & bad & good & 20130211/ & 91.5 & good & bad \\
\hline 20110927/ & 89 & good & good & $20130216 /$ & 94.8 & bad & bad \\
\hline 20111017/ & 92.5 & good & bad & 20130403/ & 94.3 & bad & -- \\
\hline 20111019/ & 88.5 & bad & good & -- & 94.9 & bad & good \\
\hline 20111020/ & 96 & bad & good & 20130405/ & 92.1 & bad & good \\
\hline-- & 92.9 & bad & good & 20130423/ & 89 & bad & good \\
\hline 20111027/ & 96.7 & bad & good & 20130428/ & 96.5 & good & bad \\
\hline 20111028/ & 99.1 & bad & good & $20130429 /$ & 94.2 & bad & good \\
\hline 20111101/ & 91.8 & -- & bad & $20130509 /$ & 97.5 & good & good \\
\hline-- & 90.5 & -- & bad & $20130512 /$ & 92.5 & bad & bad \\
\hline 20111111/ & 91.5 & bad & good & 20130513/ & 92 & good & bad \\
\hline-- & 91.3 & bad & -- & -- & 98.3 & good & -- \\
\hline 20111112/ & 95 & bad & -- & -- & 97.1 & good & -- \\
\hline 20111113/ & 94 & bad & bad & 20130514/ & 93.1 & bad & -- \\
\hline-- & 96.1 & bad & bad & 20130515/ & 95.1 & good & good \\
\hline-- & 91.4 & bad & -- & $20130528 /$ & 96.1 & -- & -- \\
\hline-- & 91.6 & bad & -- & -- & 97.7 & -- & -- \\
\hline 20111130/ & 94.1 & bad & bad & -- & 95.3 & -- & -- \\
\hline-- & 98.5 & bad & -- & -- & 97.7 & -- & -- \\
\hline-- & 92.6 & bad & bad & -- & 90 & -- & -- \\
\hline-- & 90.1 & bad & bad & -- & 88.2 & -- & -- \\
\hline 20111211/ & 90.1 & bad & good & 20130531/ & 96.3 & good & bad \\
\hline $20111212 /$ & 91.4 & good & good & 20130608/ & 91.5 & good & good \\
\hline 20111218/ & 91.7 & -- & good & 20130609/ & 94.4 & good & good \\
\hline-- & 91.5 & -- & good & -- & 94.7 & good & --- \\
\hline-- & 90.4 & -- & -- & $20130612 /$ & 94.2 & good & -- \\
\hline 20111224/ & 94.5 & bad & -- & -- & 94.1 & good & -- \\
\hline-- & 96.5 & bad & good & -- & 89.9 & bad & good \\
\hline 20111229/ & 94.3 & bad & good & 20130618/ & 93 & bad & good \\
\hline 20120116/ & 100.1 & bad & good & 20130619/ & 91.2 & good & good \\
\hline 20120206/ & 95.5 & bad & good & -- & 96.4 & bad & good \\
\hline-- & 97.3 & bad & good & -- & 98.9 & bad & good \\
\hline 20120223/ & 92.6 & bad & bad & -- & 95 & bad & good \\
\hline
\end{tabular}




\begin{tabular}{|c|c|c|c|c|c|c|c|}
\hline-- & 95.9 & bad & good & $20130620 /$ & 93.8 & bad & good \\
\hline $20120224 /$ & 90.5 & bad & -- & $20130624 /$ & 90.2 & bad & good \\
\hline $20120301 /$ & 92.3 & bad & -- & -- & 97.8 & good & good \\
\hline-- & 97.6 & bad & -- & $20130625 /$ & 98.4 & good & bad \\
\hline-- & 96.5 & bad & bad & $20130626 /$ & 93.4 & good & -- \\
\hline $20120304 /$ & 93.9 & bad & good & -- & 94.8 & good & good \\
\hline-- & 95.4 & bad & bad & $20130628 /$ & 97.7 & good & bad \\
\hline $20120306 /$ & 96.8 & bad & bad & $20130630 /$ & 92.8 & good & good \\
\hline-- & 92.7 & bad & good & -- & 94.9 & bad & -- \\
\hline $20120317 /$ & 92.7 & bad & -- & -- & 98.6 & good & -- \\
\hline-- & 93.2 & bad & good & $20130703 /$ & 93.4 & good & good \\
\hline $20120318 /$ & 92.5 & good & -- & -- & 90.2 & bad & good \\
\hline-- & 94.6 & bad & bad & $20130705 /$ & 96.3 & good & good \\
\hline-- & 91.5 & bad & -- & $20130809 /$ & 95.3 & bad & good \\
\hline-- & 93.5 & good & -- & $20130810 /$ & 96.6 & good & good \\
\hline $20120412 /$ & 92.5 & bad & good & $20130907 /$ & 94.3 & good & good \\
\hline $20120414 /$ & 93 & bad & good & & 96.9 & good & good \\
\hline
\end{tabular}


Table 7 Simultaneous observations of sporadic Fe layers and electric fields during the METAL Campaign (Kirkwood and Zahn, 1993)

\begin{tabular}{|c|c|c|c|c|c|}
\hline Date & $\begin{array}{l}\text { Onset of } \\
\text { the } \mathrm{Fe}_{\mathrm{S}} \\
\text { (UT) }\end{array}$ & $\begin{array}{l}\text { Start height } \\
\text { of the } \mathrm{Fe}_{\mathrm{S}} \\
(\mathrm{km})\end{array}$ & $\begin{array}{l}\text { Occurrence } \\
\text { time of the } \\
E_{S}(U T)\end{array}$ & $\begin{array}{c}\text { Altitude of } \\
\text { the } E_{S} \text { layers } \\
(\mathrm{km})\end{array}$ & $\begin{array}{c}\text { Electric } \\
\text { field } \\
(\mathrm{m} \mathrm{V} / \mathrm{m})\end{array}$ \\
\hline 19910910/ & 2115 & 95 & 2120 & 96 & $20 \mathrm{SW}$ \\
\hline \multirow[t]{2}{*}{ 19910917/ } & 2231 & 94 & 2250 & 93 & $15 \mathrm{~S}$ \\
\hline & 0051 & 92 & & & \\
\hline \multirow[t]{2}{*}{ 19910920/ } & 2107 & 96.4 & 2130 & 97 & $10 \mathrm{~S}$ \\
\hline & 2321 & 94 & & & \\
\hline \multirow[t]{2}{*}{$19910922 /$} & 2257 & 103 & 2257 & 103 & $3 \mathrm{~S}$ \\
\hline & $23: 14$ & 92 & 3 & & \\
\hline
\end{tabular}




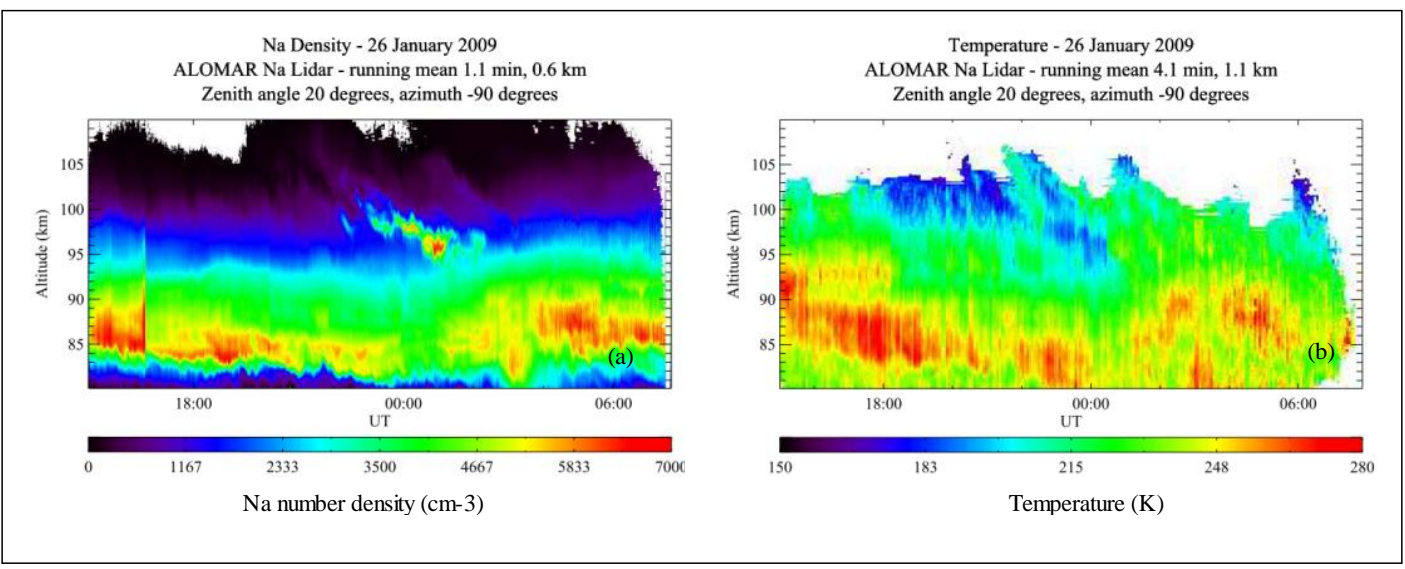

Figure 1 (a) A sporadic sodium layer observed by ALOMAR wind/temperature lidar on January 26, 2009 locating at the edge of the sodium layer (Østerpart, 2011). (b) Temperature image on this night, showing that the SSL occurred in the temperature minimum (Østerpart, 2011) 


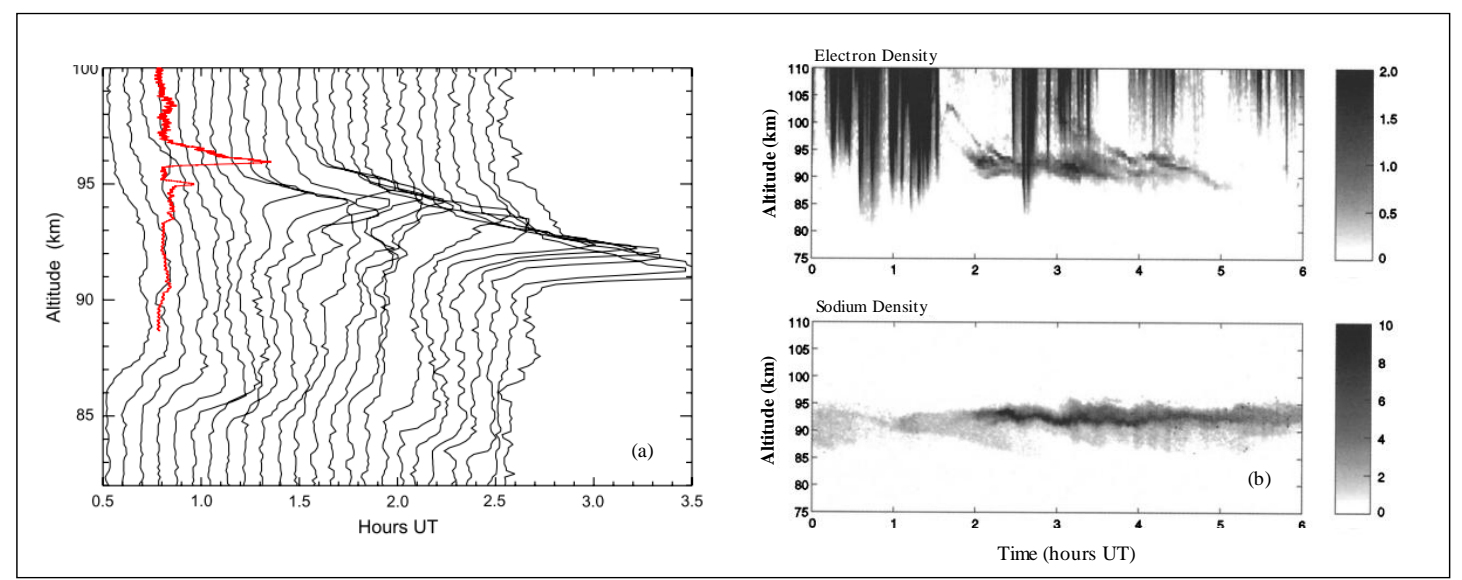

Figure 2 (a) A sporadic sodium layer (black lines) observed by the wind/temperature lidar at ALOMAR and a descending $\mathrm{E}_{\mathrm{S}}$ layer (red line) observed by a rocket on July 5, 2002 (Williams et al., 2006). The electron layer occurred about twenty minutes before the onset of the SSL. The descending $\mathrm{E}_{\mathrm{S}}$ layer was located very closed to the start altitude of the SSL, with a peak density of $10^{5}$ electron $/ \mathrm{cm}^{-3}, 10$ times larger than the peak density of the SSL with a value of $5000 \mathrm{Na}$ atoms $/ \mathrm{cm}^{-3}$ (Williams et al., 2006). (b) Another SSL event, observed by the sodium lidar on November 11, 1997, at Sondrestrom $\left(66^{\circ} 59^{\prime} \mathrm{N}, 50^{\circ} 57^{\prime} \mathrm{W}\right)$, was accompanied by strong $E_{S}$ layers observed by the nearby VHF radar (Heinselman et al., 1998). The electron layer and SSL occurred near at the same time and same height (Heinselman et al., 1998) 


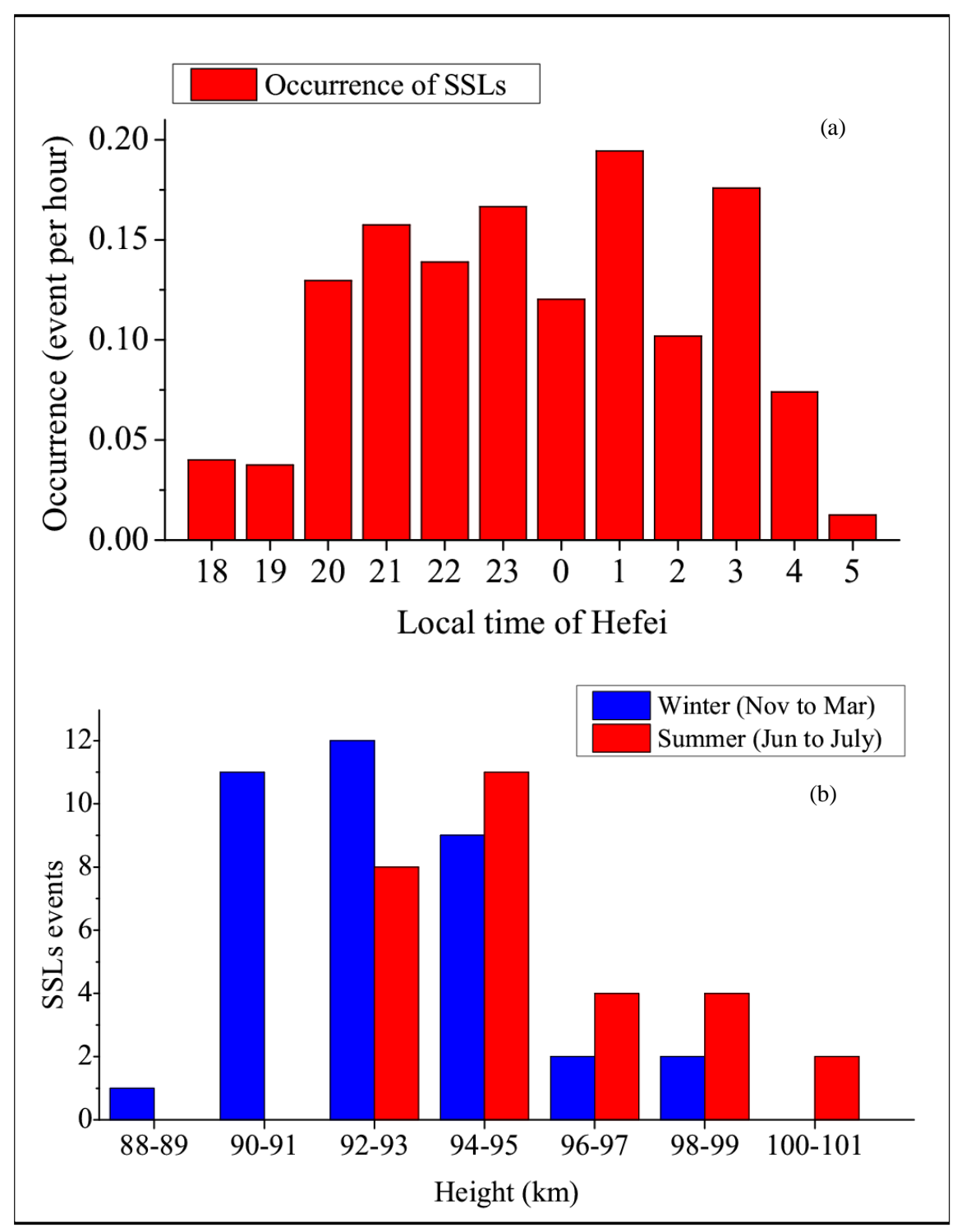

Figure 3 (a) The distribution of the start time of SSLs in Hefei from 2011 to 2013:

SSLs occur frequently throughout 20 LT to 03 LT. (b) The distributions of peak altitudes in summer (red column) and in winter (blue column) 


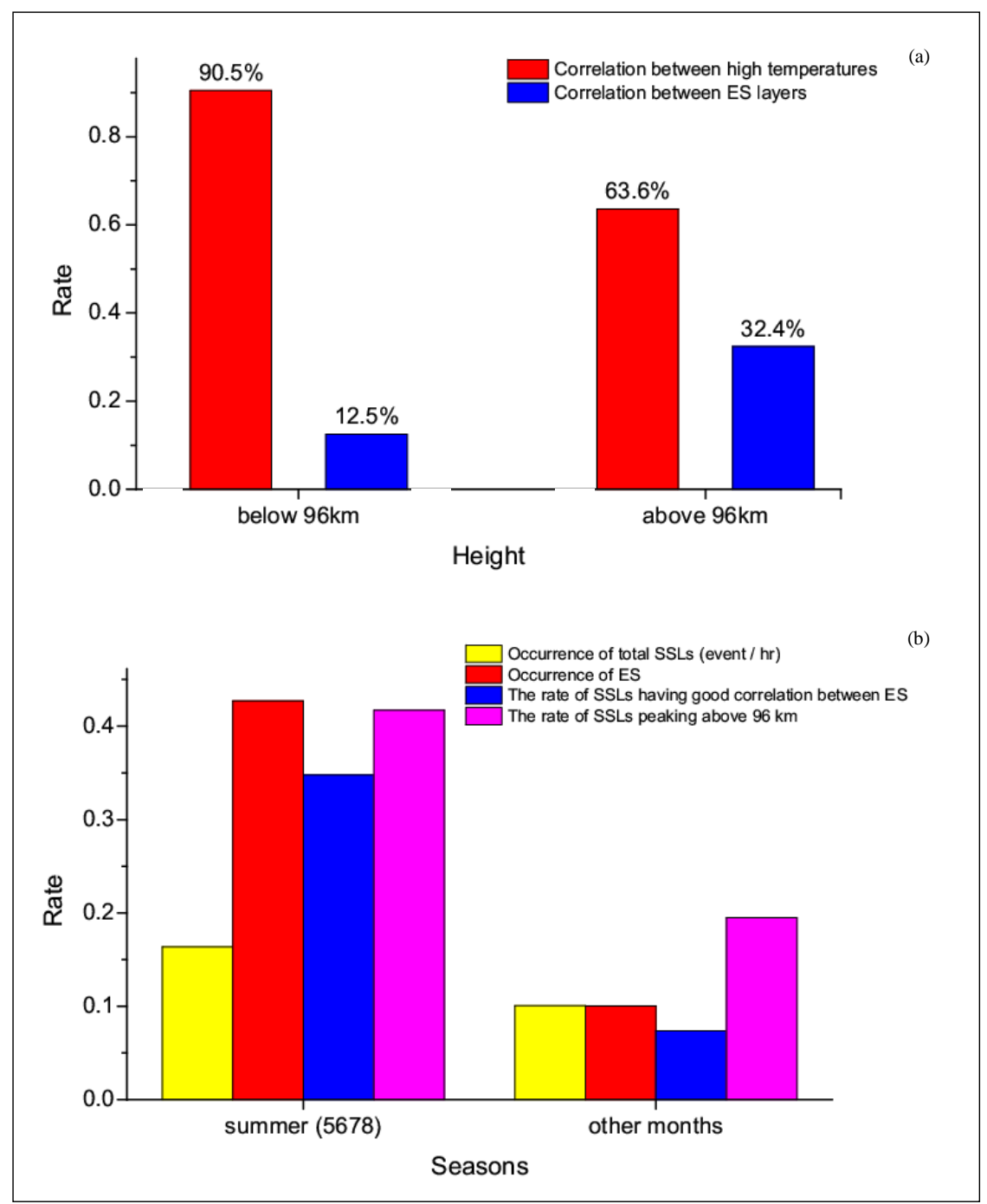

Figure 4 (a) Relationship between SSLs and $\mathrm{E}_{\mathrm{S}}$ (blue column) and relationship between SSLs and high temperature (red temperature) in different altitude at Hefei. Below 96 km: SSLs had a good correlation with high temperatures, but the correlation between SSLs and $\mathrm{E}_{\mathrm{S}}$ layers is very weak. Above $96 \mathrm{~km}$ : the correlation between SSLs and high temperature is lower than that below $96 \mathrm{~km}$, but the correlation between SSLs and Es is better. (b) Occurrence frequencies of total SSLs (yellow column), Occurrence frequencies of $E_{S}$ layers (red column), rate of good links between SSLs and $E_{S}$ (blue), and the rate of SSLs above $96 \mathrm{~km}$ (pink) in summer (left) and non-summer time (right). 


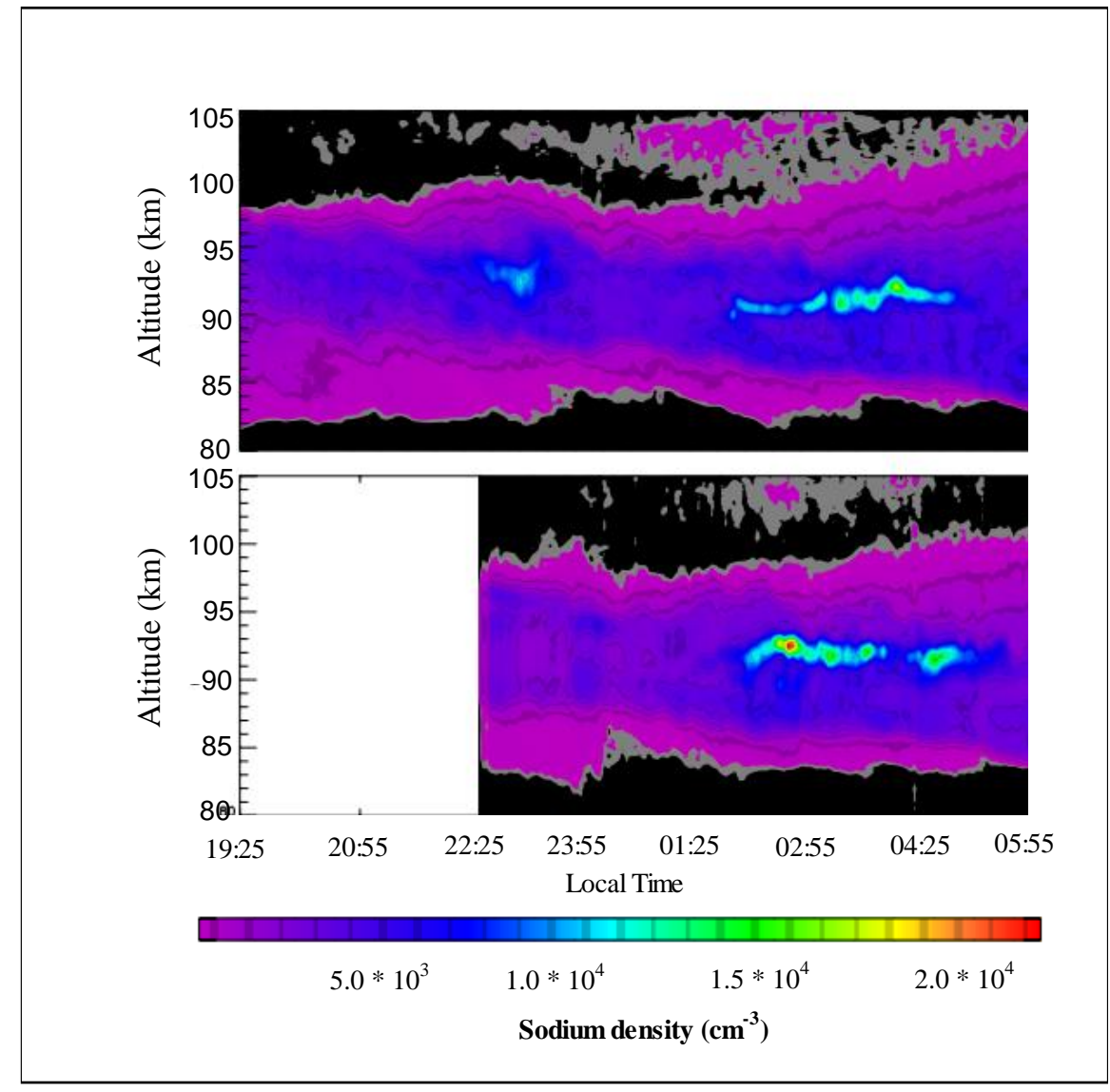

Figure 5 A typical SSL observed on November 2, 2007 by both the University of Science and Technology of China (USTC) lidar (upper image) and Wuhan Institute of Physics and Mathematics (WIPM) lidar (lower image) (Dou et al., 2009) 


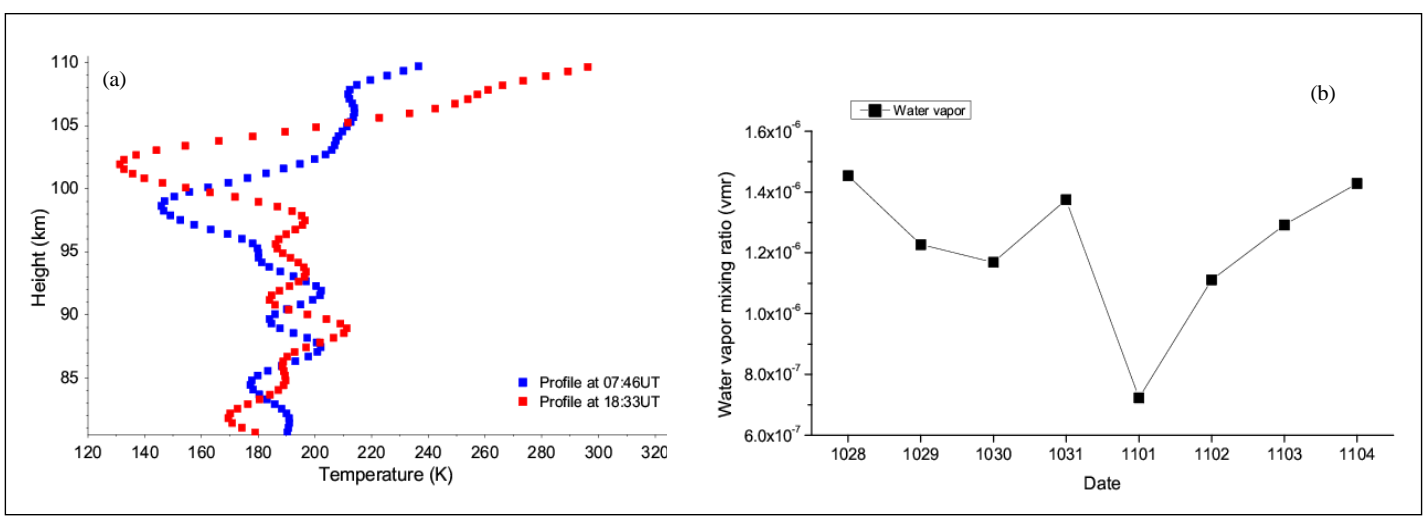

Figure 6 (a) Temperature profiles before the SSL event, with an extremely low temperature of $146 \mathrm{~K}$ at $99 \mathrm{~km}$ at 07:48 UT (15:48 LT, LT=UT+8) on October 31 (blue line) and $131 \mathrm{~K}$ at $102 \mathrm{~km}$ at 18:33 UT (02:33 LT in the early morning of Nov 1) (red line) (b) Variations of water vapor content from MLS, with a sharp decrease on November 1, one day before the SSL and a recovery after the SSL 


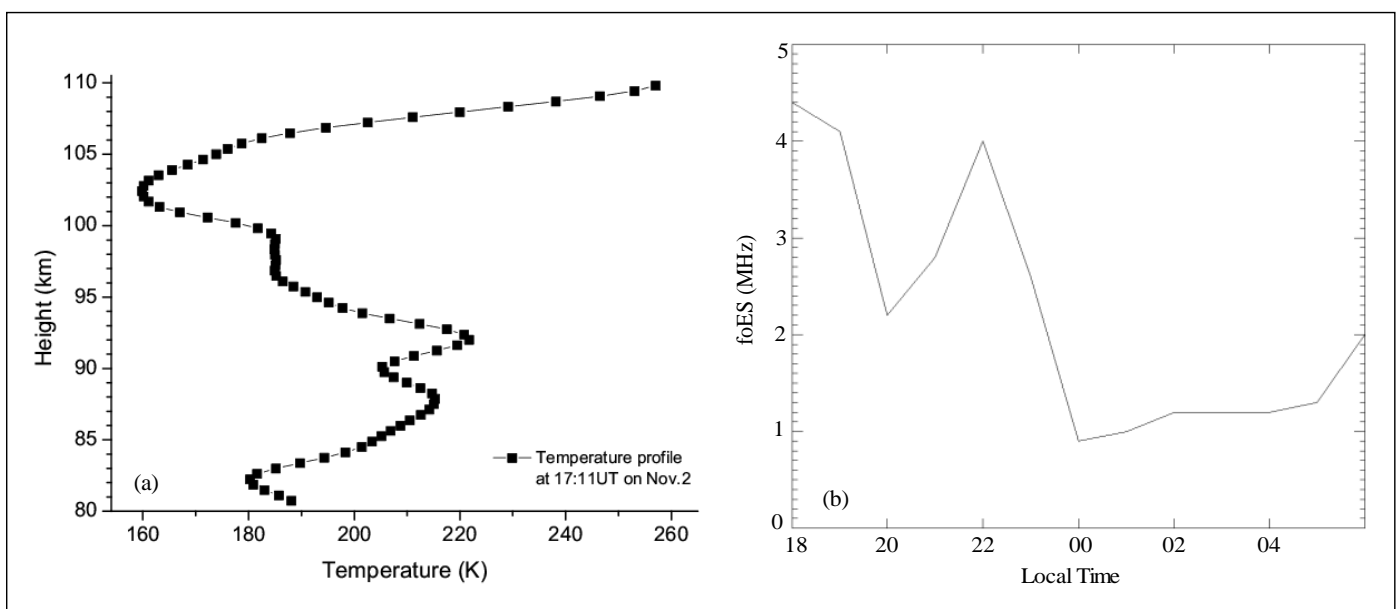

Figure 7 (a) Temperature profile at 17:11 UT on November 2 (1:11 UT on November 3), with a maximum temperature of $222 \mathrm{~K}$; (b) Activities of $E_{S}$ layers on November 2, showing a weak peak at $22 \mathrm{LT}$ with a foE $\mathrm{S}_{\mathrm{S}}$ value of $4 \mathrm{MHz}$ (Dou et al., 2009) 


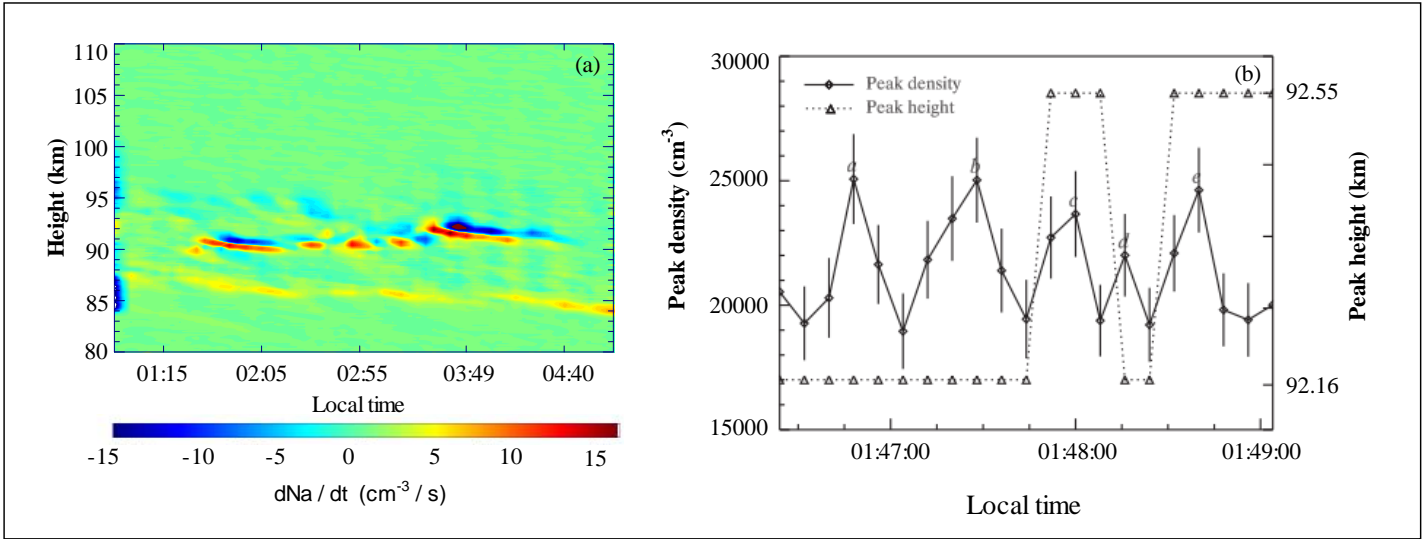

Figure 8 (a) Differential chart of the sodium density on the night of November 2, 2007.

(b) The bursts of sodium atoms during the SSLs, sampled from 01:46:24 LT to 01:49:04 LT by WU lidar (Liu and Yi, 2009) 


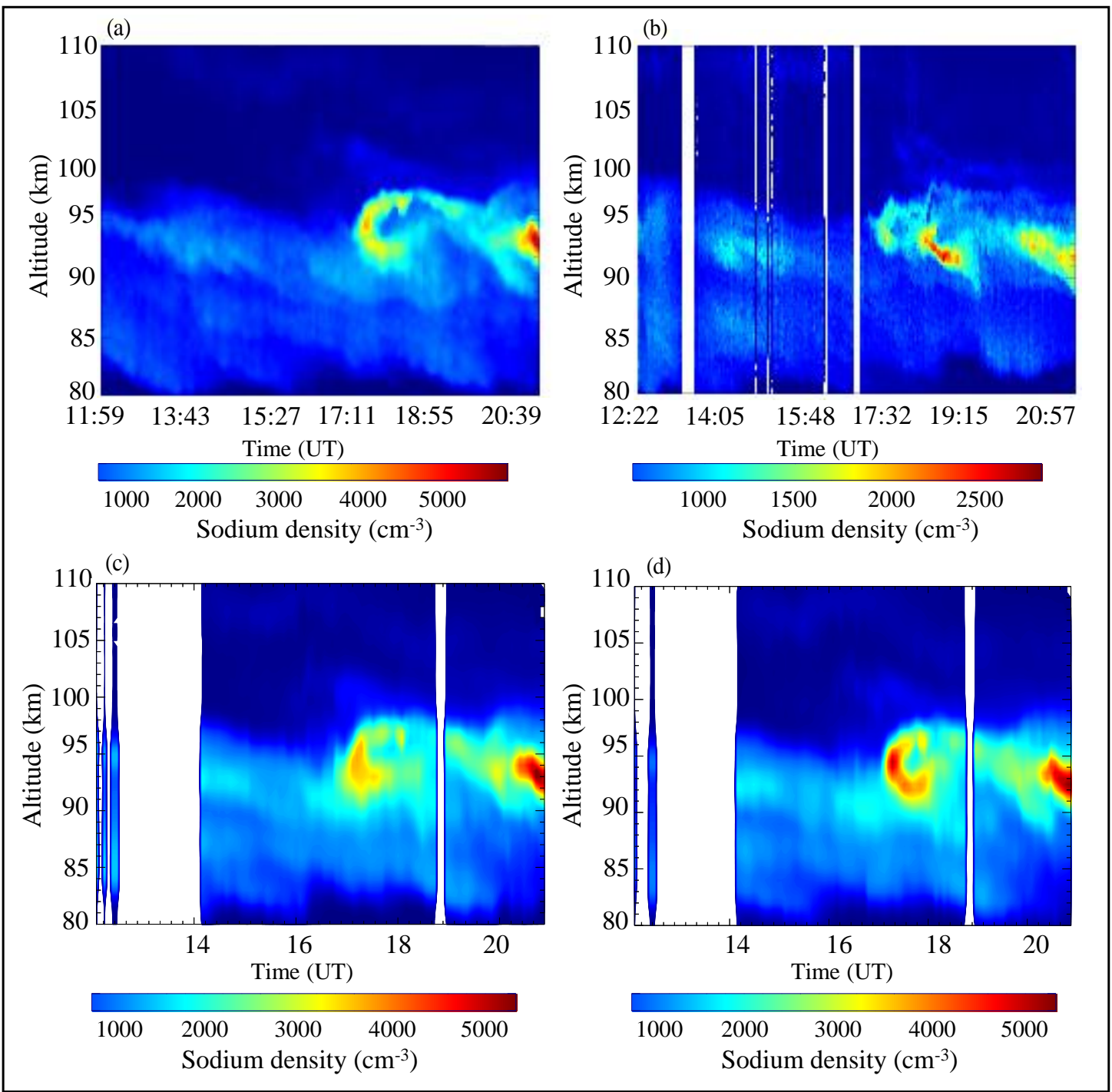

Figure 9 (a) Development of sodium density on May 13, 2013, observed by USTC sodium lidar from 11:59 UT to 20:39 UT with the SSL lasting from 16:55 UT to 19:13UT. (b) Sodium density variation observed by WIPM lidar at Wuhan. (c) Sodium density variation observed by the east beam of USTC T/W lidar. (d) Sodium density variation observed by the north beam of T/W lidar. 


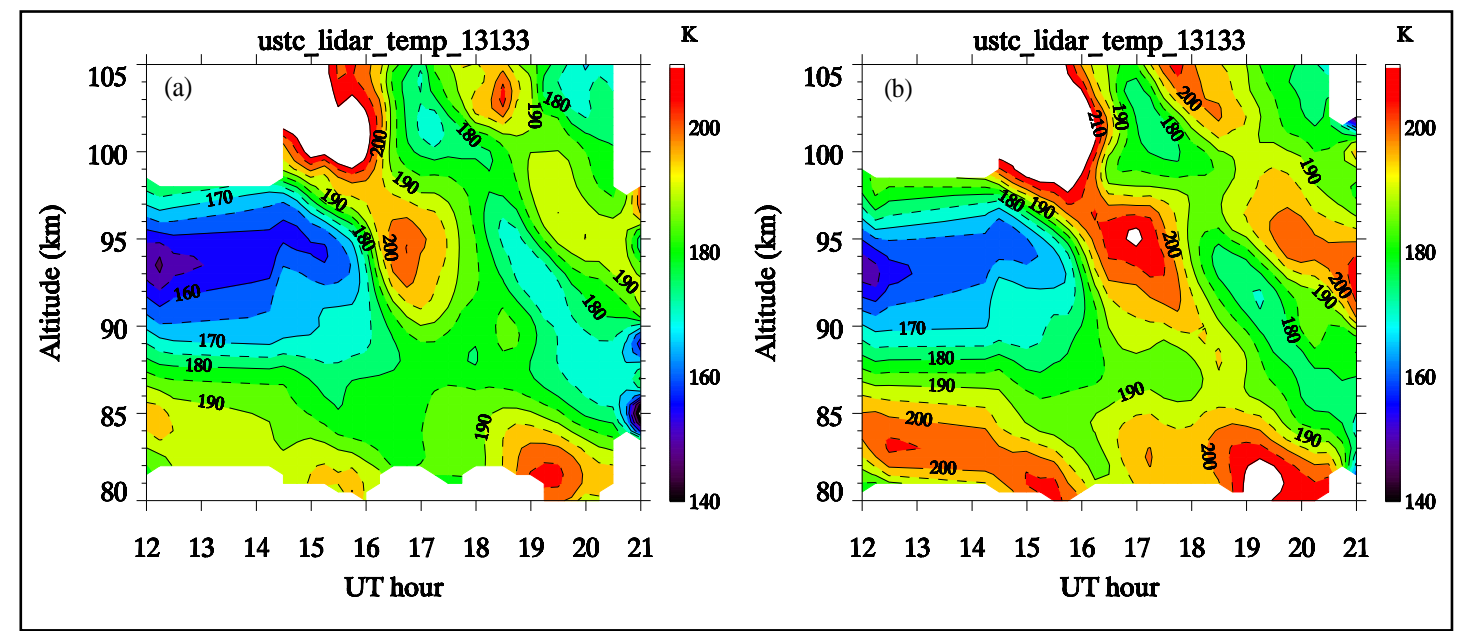

Figure 10 Temperature on the night of May 13, 2013, from the USTC wind/temperature lidar east beam (a) and north beam (b) 

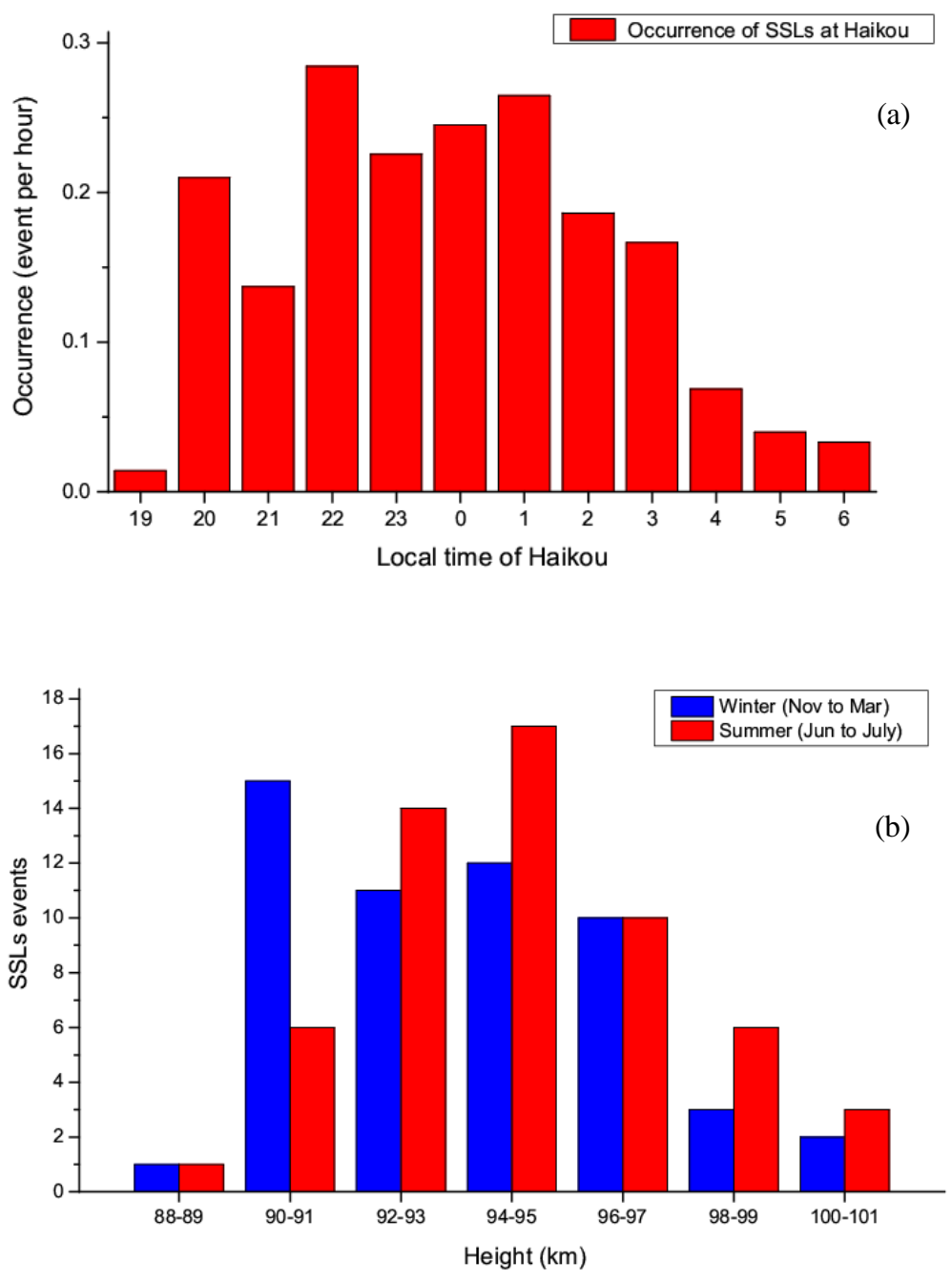

Figure 11 (a) The distribution of the onset time of the SSLs observed by the Haikou sodium lidar from January 2011 to December 2013. (b) The seasonal distribution of the peak altitudes of the SSLs in Haikou, with a lower location for the winter SSLs and higher location for the summer SSLs 


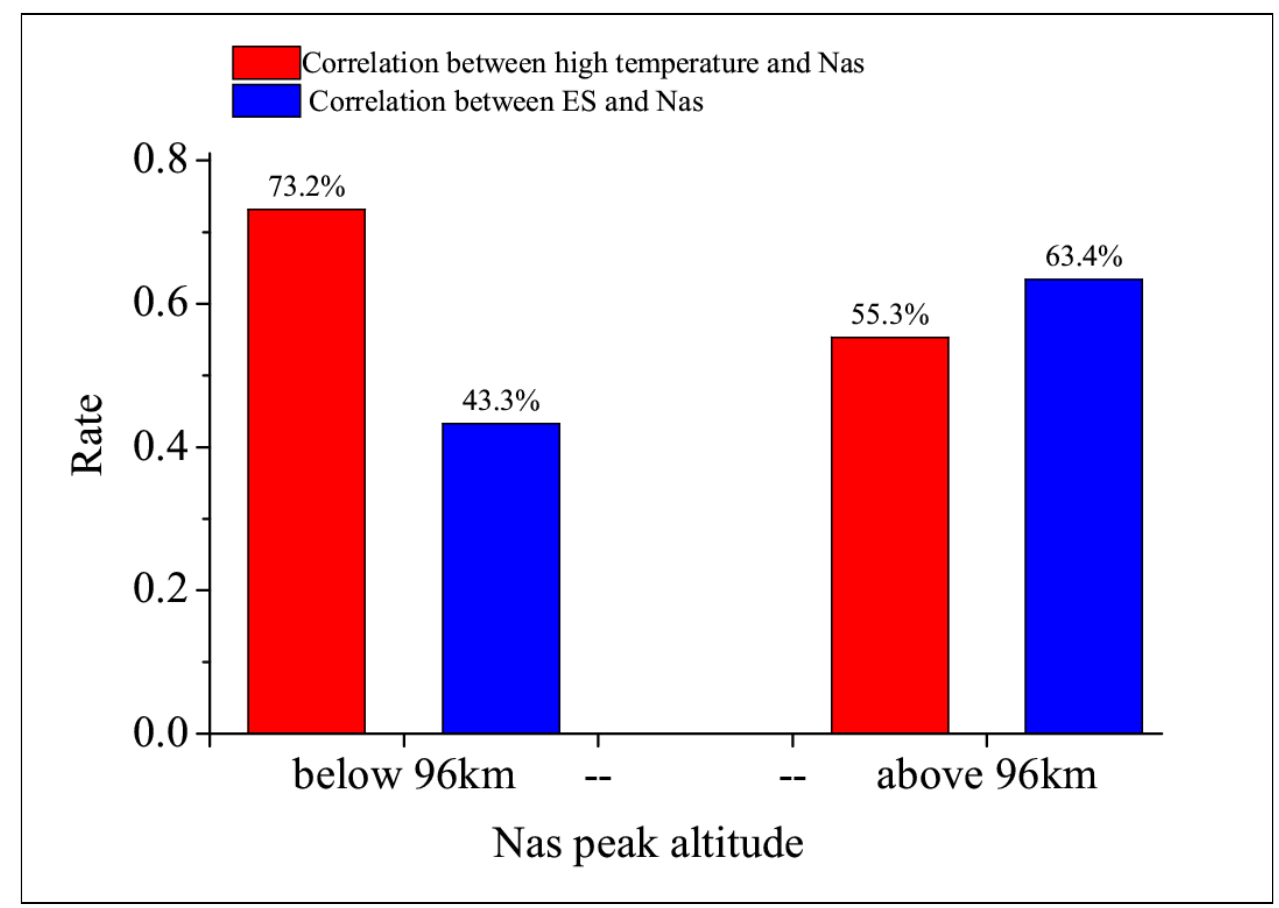

Figure 12 Relationship between SSLs, $\mathrm{E}_{\mathrm{S}}$ and high temperature in different altitudes in Haikou station 

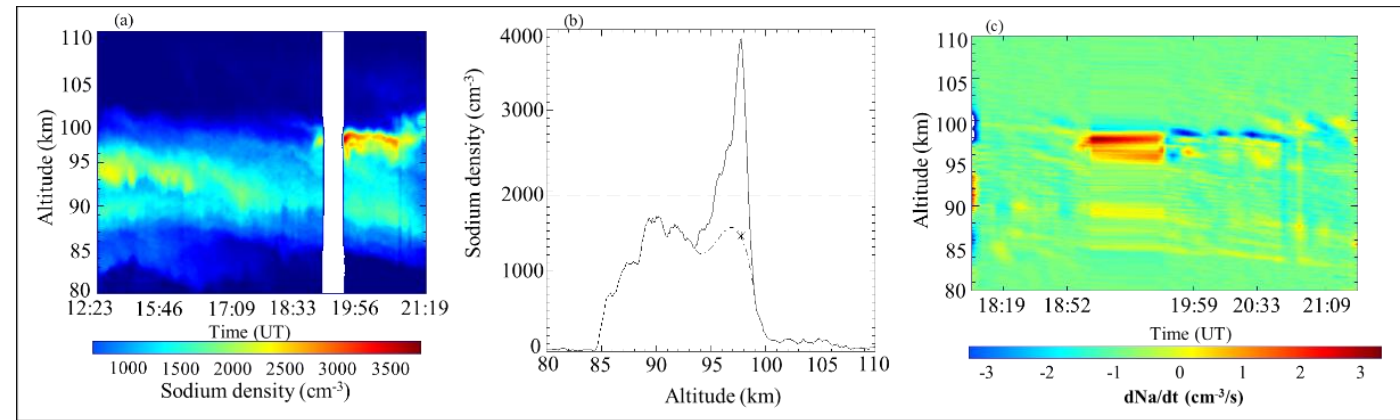

Figure 13 (a) A SSL event starting at 19:01 UT with a high peak altitude at $97.7 \mathrm{~km}$ observed by the Haikou sodium lidar On June 28, 2013. (b) The peak density profile of this SSL. (c) Differential chart of sodium atom density variation of this event 


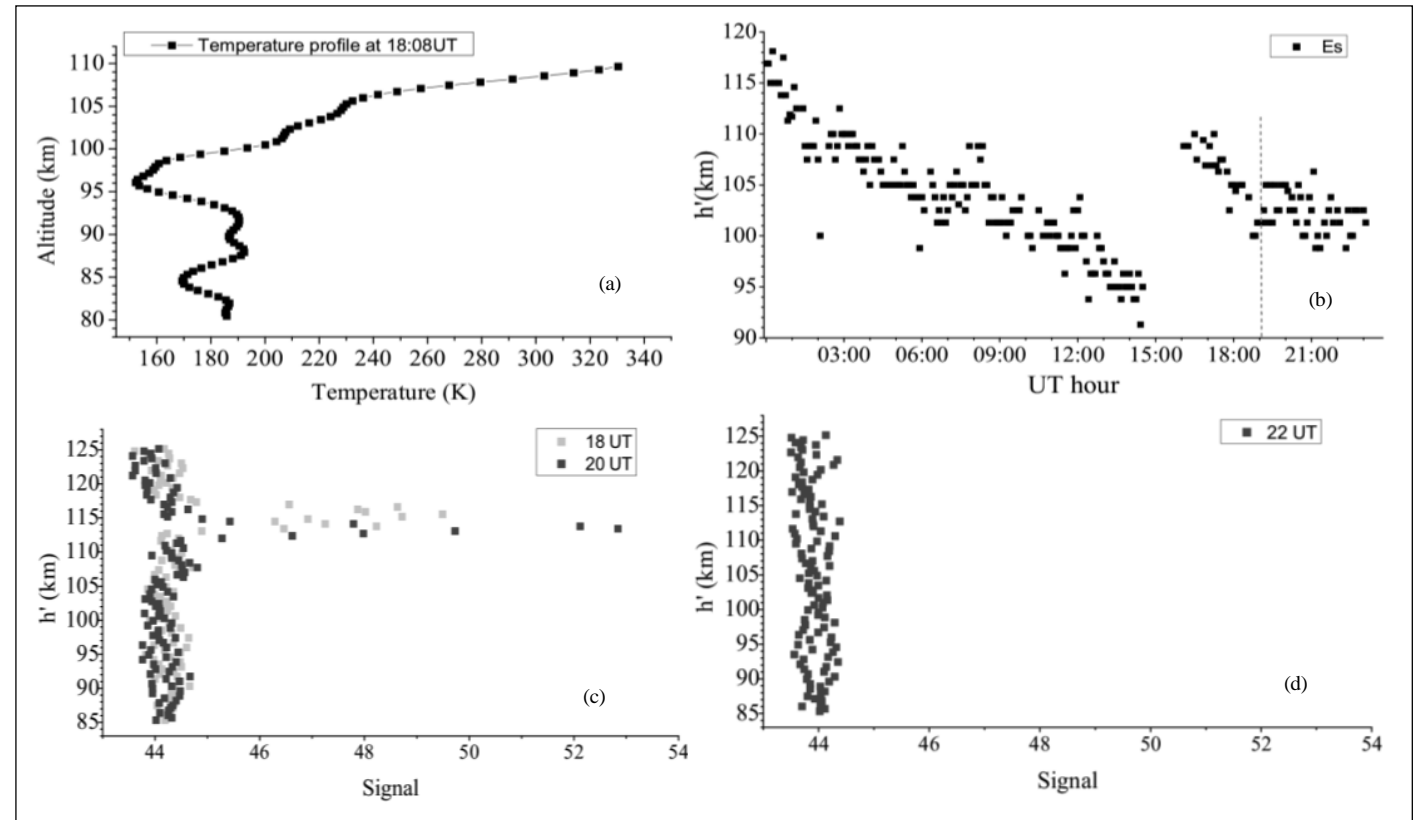

Figure 14 (a) Temperature profile at 18:08 UT by SABER, with a minimum of $159 \mathrm{~K}$ at the peak altitude of the SSL at $97.7 \mathrm{~km}$. (b) The altitude of $E_{S}$ observed by the ionosonde throughout the SSL event, showing a succession of obvious downward sporadic E layers. The sporadic sodium layer occurred during the downward propagation of the $E_{S}$ (gray dash) (c) Plasma irregularity echoed observed by the nearby VHF radar, with a distinct peak at 18 UT and 20 UT. (d) No irregularity remained at $22 \mathrm{UT}$. 

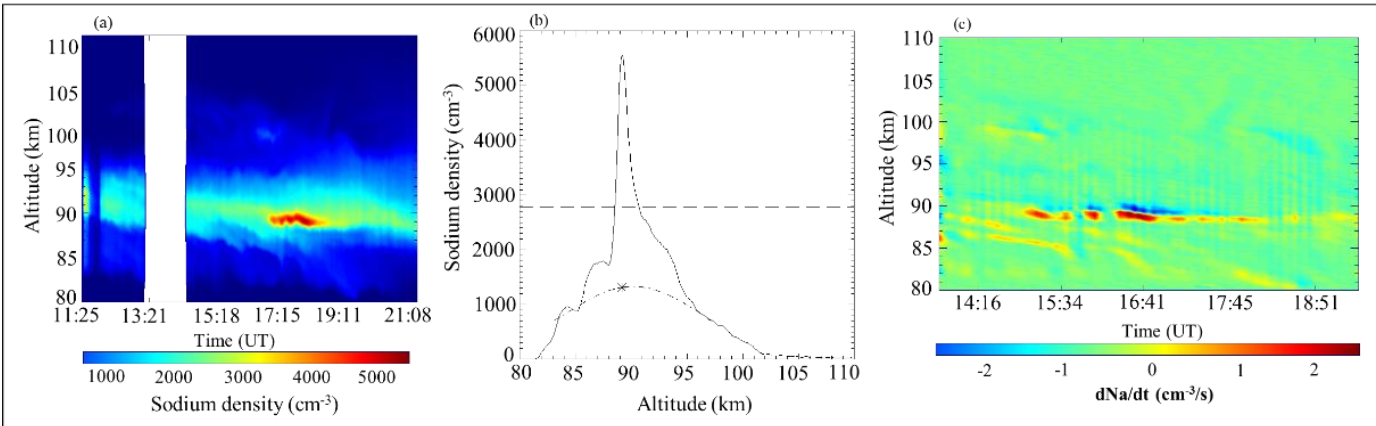

Figure 15 (a) The contour image of the sodium layer when an SSL event occurred on November 9, 2012 at Haikou station. (b) The peak density profile of this SSL. (c) The sodium atom density variations throughout this SSL 


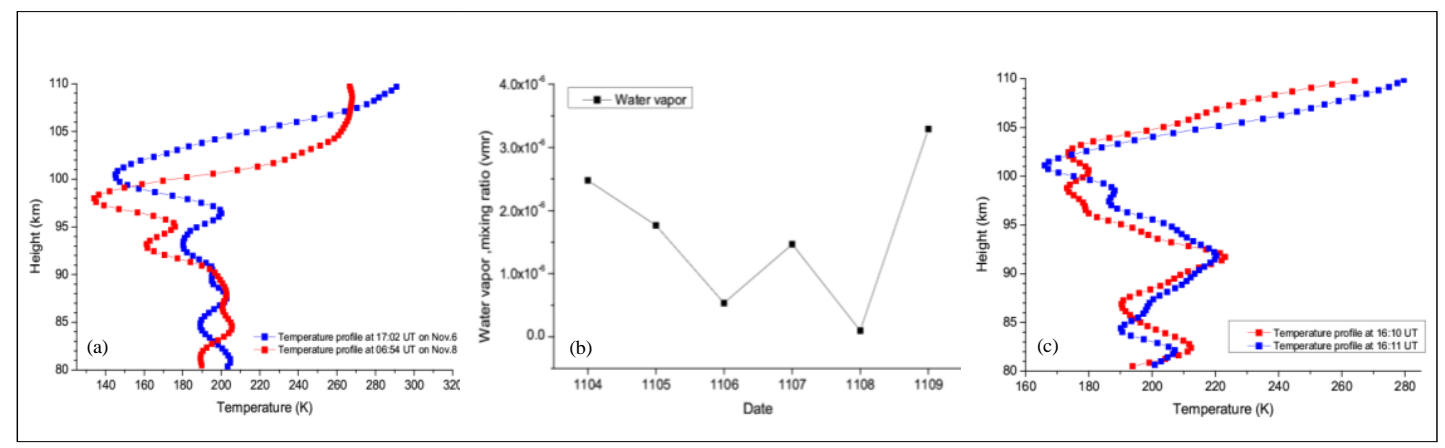

Figure 16 (a) Temperature profiles on November 8, one day before the SSL. (b) Variations of water vapor content before and after the SSL, with a sharp decrease on November 8. (c) Temperature profile during the SSL 


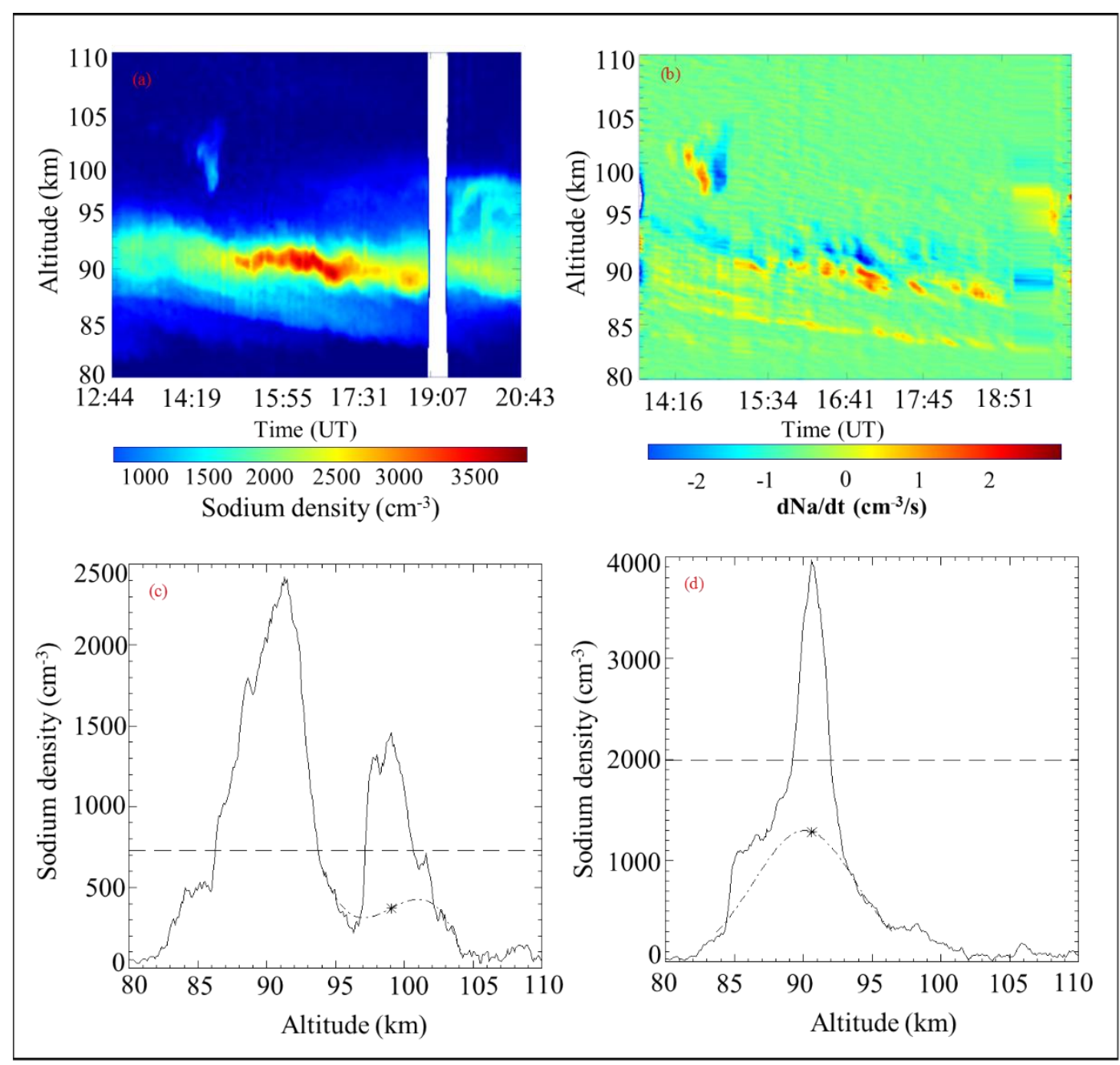

Figure 17 (a) Two distinct sporadic sodium events on August 31, 2011 at Haikou, with SSL-1 locating near $99 \mathrm{~km}$ and SSL-2 at $91 \mathrm{~km}$ altitude. (b) Differential chart for the sodium atom density throughout this night. SSL-1 had a very rapid increase of sodium atoms, and soon a quick dissipation of sodium, with no continuous burst character. SSL-2 had a similar burst form to the typical SSL event on December 2, 2007 at Hefei and Wuhan. (c) Peak density profile for SSL-1 at 22:44 LT (14:44 UT). (d) Peak density profile for SSL-2 at 0:27 LT (16:27 UT) 


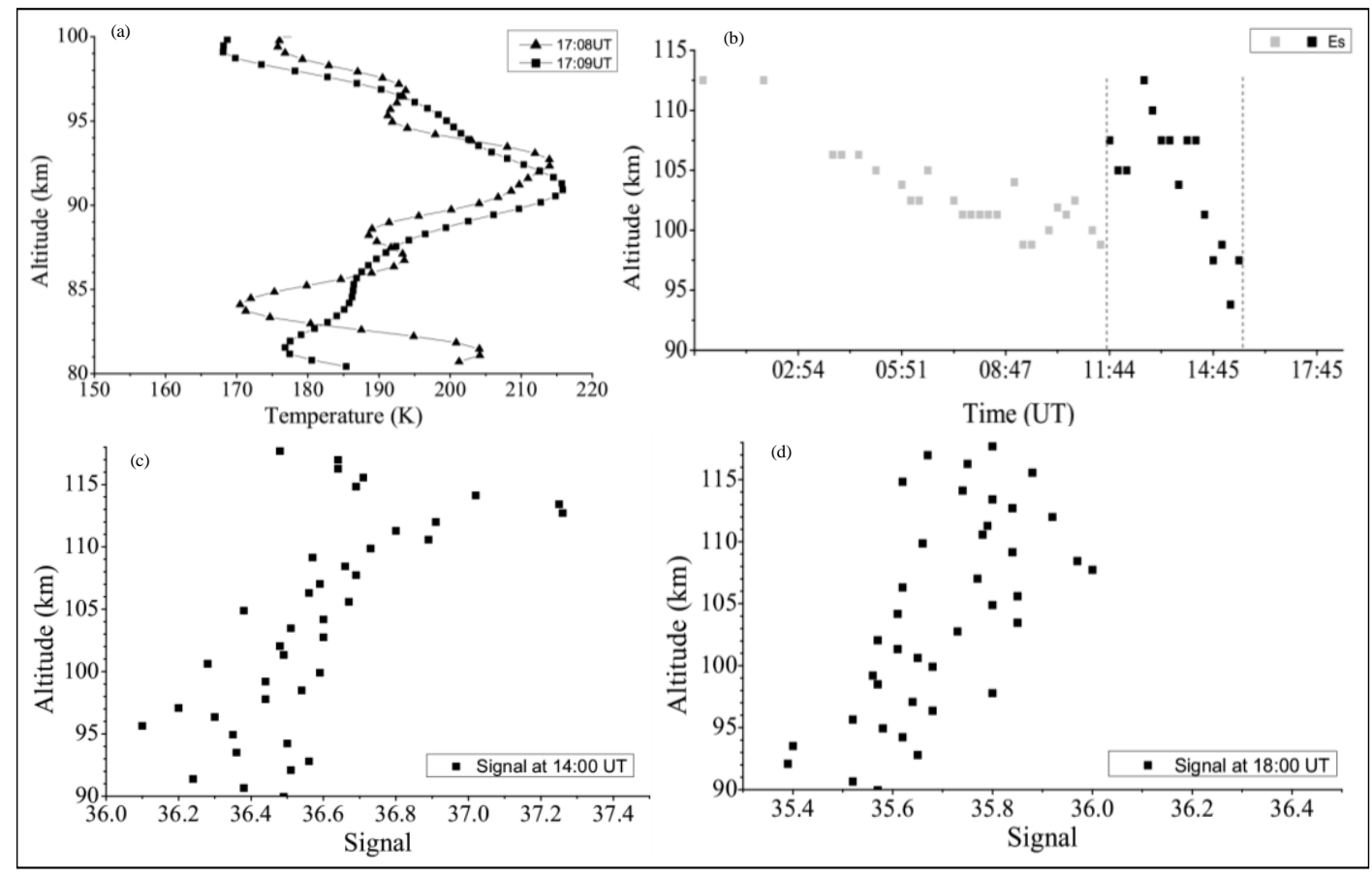

Figure 18 (a) Temperature profiles sampled at 17:08 UT (01:08 LT) and 17:09 UT (01:09 LT) when the sodium atoms increasing rapidly, about 1 hour before SSL-2 reached its peak density. Temperature profiles showed high values (over $200 \mathrm{~K}$ ) between 89.7 and $93.8 \mathrm{~km}$, overlapping the region of SSL-2. A temperature maximum value of $214 \mathrm{~K}$ occurred at $92.3 \mathrm{~km}$, also close to the peak altitude of SSL-2 at 90.6 km. (b) Altitude of $E_{S}$ observed by the ionosonde on August 31, 2011, showing active downward propagation of $\mathrm{E}_{\mathrm{S}}$ layers before SSL-1 (scatters between gray dash), but no $E_{S}$ occurred throughout SSL-2 with a duration more than four hours. (c) Plasma irregularities observed by Haikou VHF radar at 14:00 UT, twenty minutes before SSL-1. (d) VHF radar sample at 18:00 UT while SSL-2 was still in the rising stage, without obvious peak of irregularity echoes. 


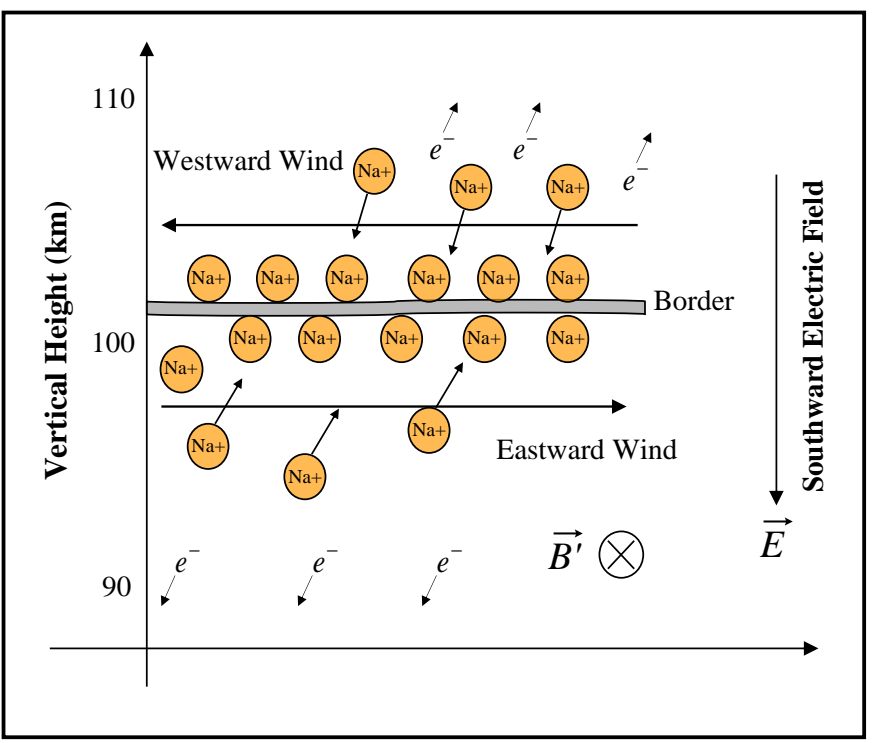

Figure 19 Mechanism for the formation of $E_{S}$ in the north hemisphere: sodium ions converge in the border of the zonal wind shear under the influence of wind shear and horizontal geomagnetic field. The directions of electric field and geomagnetic field were suggested by (Kirkwood, 1997). The converged sodium ion layer would descend to a lower height due to the southward electric field and form a low altitude $\mathrm{E}_{\mathrm{S}}$ 


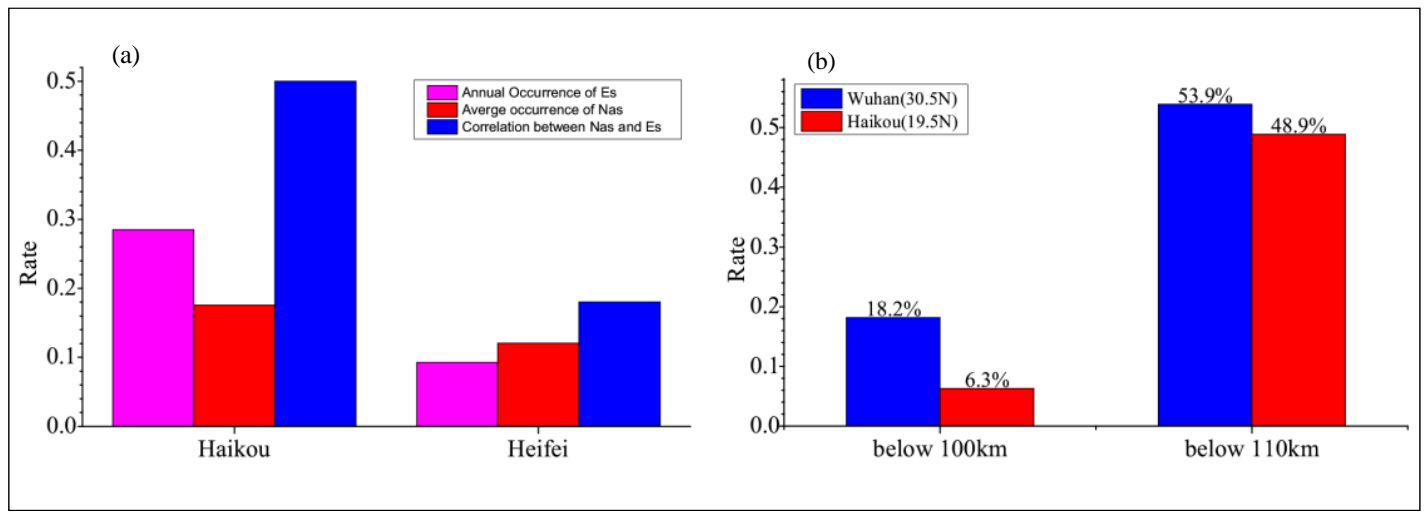

Figure 20 (a) Annual average occurrence frequencies of $E_{S}$ (pink column) and SSLs (red column) as well as the rate of the good links between SSLs and $\mathrm{E}_{\mathrm{S}}$ (blue column) in Hefei and Haikou. (b) Ratios of low altitude $E_{S}$ layers descending below $110 \mathrm{~km}$ and $100 \mathrm{~km}$ in Wuhan $\left(30.5^{\circ} \mathrm{N}\right)$ (blue column) and Haikou $\left(19.5^{\circ} \mathrm{N}\right)($ red column$)($ this rate is defined as the ratio of numbers of $E_{S}<100 \mathrm{~km}$ over total $E_{S}$ numbers). 


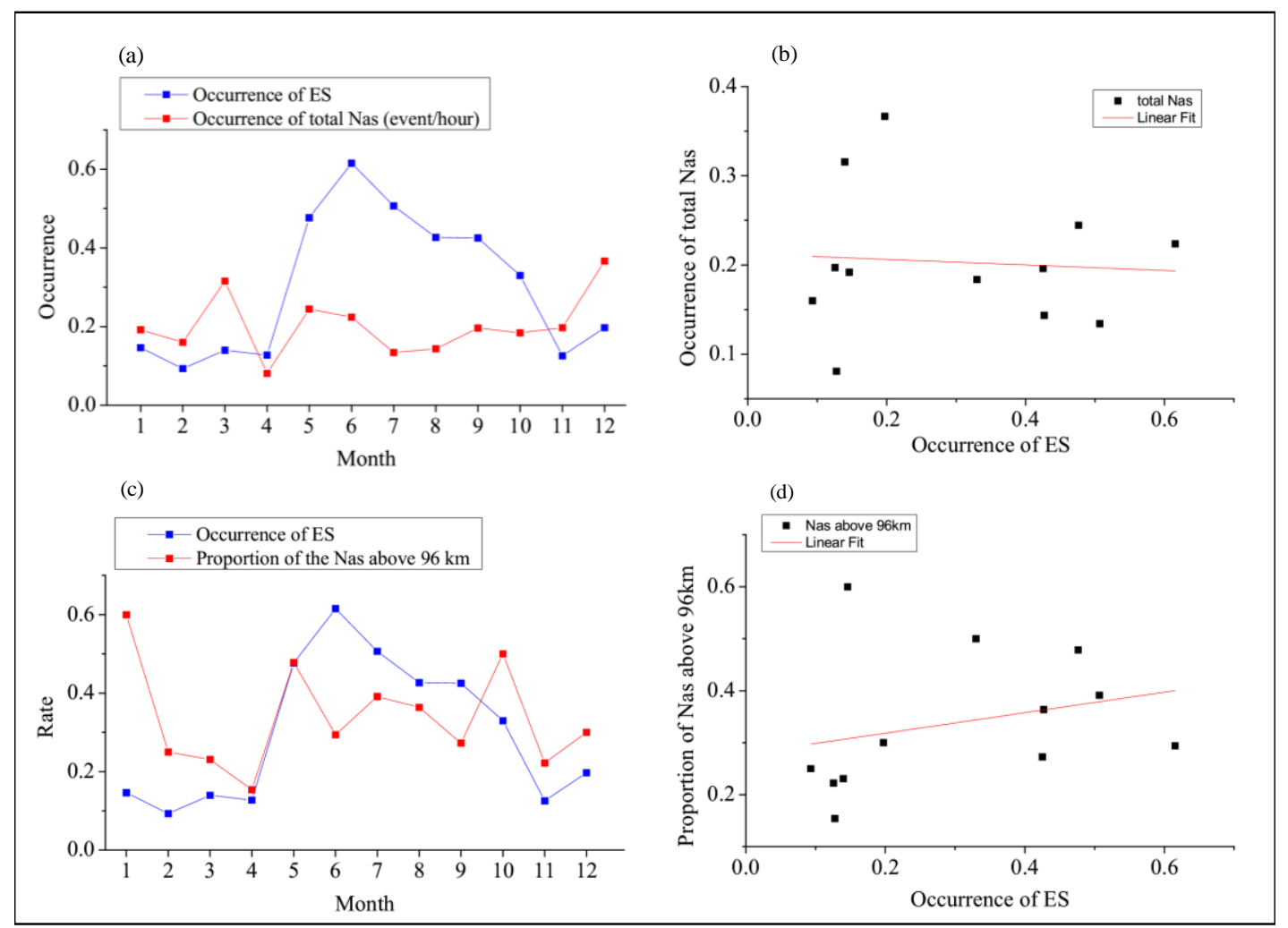

Figure 21 (a) Monthly occurrence frequency of SSLs (red line) and $E_{S}$ layers (blue line) at Haikou from 2011 to 2013. SSLs occurred more frequently in March than in summer, but $E_{S}$ layers had a low occurrence frequency in March. (b) The linear regression between the occurrence frequencies of SSLs and $E_{S}$ (correlation coefficient=-0.07, with p-value=0.82). (c) Monthly occurrence frequency of the SSLs above $96 \mathrm{~km}$ (red curve) and $\mathrm{E}_{\mathrm{S}}$ (blue curve). (d) Linear fit between monthly occurrence frequencies of the SSLs above $96 \mathrm{~km}$ and $\mathrm{E}_{\mathrm{S}}$ (correlation coefficient $=0.27$, $\mathrm{p}$-value $=0.39)$. 


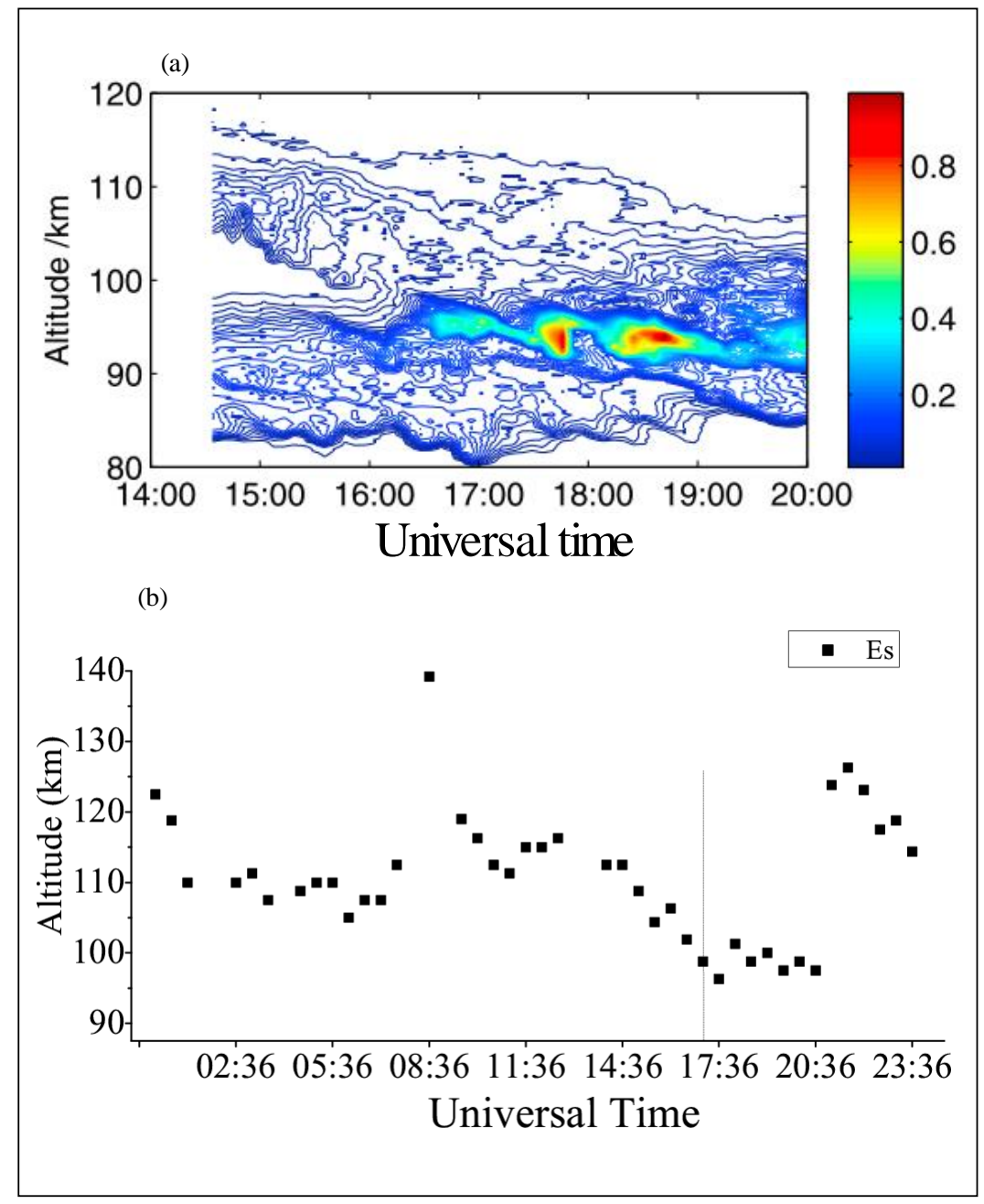

Figure 22 (a) Contour image of sodium density variations for a double sodium layer and sporadic sodium layer on May 222011 at Peking, revealing a double sodium layer forming before 14:00 UT with a second peak density at $110 \mathrm{~km}$ close to the main sodium layer density at $90 \mathrm{~km}$. As the double sodium layer descended, a sporadic sodium layer occurred at $95 \mathrm{~km}$ altitude at 16:40 UT (Wang et al., 2012); (b) $E_{S}$ echoes observed by Peking ionosonde on May 22, 2010. 